\title{
Influence of rail fastener stiffness on railway vehicle interior noise
}

\author{
Li Li ${ }^{\mathrm{a},{ }^{*}}$, David Thompson ${ }^{\mathrm{b}}$, Yingsong Xie ${ }^{\mathrm{c}}$, Qian Zhu ${ }^{\mathrm{d}}$, Yanyun Luo ${ }^{\mathrm{a}}$, Zhenyu Lei $^{\mathrm{a}}$ \\ ${ }^{a}$ Institute of Rail Transit, Tongji University, Shanghai 201804, China \\ ${ }^{b}$ Institute of Sound and Vibration Research, University of Southampton, Southampton SO17 1BJ, UK \\ ${ }^{\mathrm{c}}$ School of Urban Railway Transportation, Shanghai University of Engineering Science, Shanghai \\ 201620, China \\ ${ }^{d}$ Commercial Vehicle Technology Center, SAIC Motor Corporation Limited, Shanghai 200041, China
}

\begin{abstract}
More attention has been paid in recent years to the interior noise of railway vehicles. It has been observed that the interior noise can increase in some locations where vibrationisolation measures are used in the track structures. In order to assess the influence of vibration isolation measures on the noise levels inside railway vehicles, a field measurement campaign has been carried out. The vehicle interior noise has been measured when a train is running at different speeds over the same non-ballasted track section fitted with two types of rail fastener of different stiffnesses. Additional measurements of axlebox vibration, train floor vibration, exterior noise and rail vibration are used to investigate the influence of the fasteners further. The experimental results are compared with simulations performed using the TWINS model, considering the wheel/rail interaction, by focusing only on the relative differences between the two fastener systems. The axlebox vibration and rail vibration are predicted for a unit roughness input and the differences in rolling noise are also obtained. The predicted differences in axlebox vibration, rail vibration and rolling noise are in broad agreement with the measurement results. The results show that the fasteners with a lower stiffness cause a noisier interior environment. Around $125 \mathrm{~Hz}$ and in the frequency range 315 to $1000 \mathrm{~Hz}$, the noise levels are higher for the more elastic fastener, with an average level difference of $3 \mathrm{~dB}$ in the latter frequency range. It appears from the shape of the level difference spectra that airborne noise has most influence between 100 and $400 \mathrm{~Hz}$ and structure-borne noise has more influence between 500 and $1000 \mathrm{~Hz}$.
\end{abstract}

Key words: Elastic rail fastener; interior noise; stiffness; railway track; acoustic response

*Corresponding author: Institute of Rail Transit, Tongji University, Building F, No. 4800, Caoan Road, Shanghai, China, 201804

E-mail address: lilee@tongii.edu.cn (L. Li). 


\section{Introduction}

Modern railway trains are required to provide their passengers with a comfortable ride in order to maintain commercial competitiveness: an important aspect of such comfort is the internal noise and vibration. However, less attention is often paid to the vibration and noise within railway vehicles than to the external environmental noise [1].

The most important source of noise in railways is the rolling noise caused by wheel and rail vibration. For trains in tunnels, however, the main environmental impact of running trains is ground-borne noise, caused by vibration propagating through the ground to nearby properties, where it radiates low frequency noise. Decreasing the stiffness of the track is one of several countermeasures deployed against ground-borne noise [2, 3]. In [4] it is shown from measurements that, when the track support stiffness is reduced, lower levels of vibration on the floor of the tunnel are clearly seen. Various types of vibration-isolating trackforms are used in practice, including resilient rail fasteners, under-sleeper pads, underballast mats, booted sleepers, or floating slab tracks $[5,6]$. Each mitigation measure on track has a particular insertion loss and effective frequency range [6]. In these studies of the vibration reduction, the interior noise has not been taken into account.

However, many people complain that the noise inside the trains becomes louder in particular areas where vibration reduction measures are installed. Wang et al. [7] presented measurements of in-car noise and floor vibration from a metro line with different track systems. It was found that the in-car noise was much higher on floating slab sections and there was a difference of about $4 \mathrm{~dB}$ between a type of soft fastener and the standard baseplate track. Higher noise levels were found on curved sections and in at least one case this was associated with rail corrugation.

In recent decades, researchers have begun to pay attention to the interior noise problems in vehicles, including investigations of source mechanisms [8]-[12], transfer path analysis [13] and interior noise evaluation. Eade and Hardy [8] discussed the mechanisms by which noise reaches the interior of a rail vehicle, including airborne and structure-borne paths. They pointed out that the noise spectrum inside modern trains is dominated by low frequency components due to the increased isolation against airborne sound transmission and the increased acoustic absorption at high frequencies. The most important sources of interior noise include wheel/rail rolling noise, traction noise and noise from fans including the heating, ventilation and air-conditioning system; at high speeds aerodynamic noise is also important. Noise is transmitted from the various sources to the interior by means of both airborne and structure-borne paths. Structure-borne noise tends to dominate the lower frequencies and airborne noise the higher frequencies [5]. The airborne paths involve transmission through the floor, walls, windows, doors and the gangway connection as well as through gaps in the door seals.

Kim et al. [14] evaluated the interior noise of an urban railway vehicle when it passed straight, curved, turnout and rail lubricator sections. From the sound pressure spectra in onethird octave bands, when the speed was $60 \mathrm{~km} / \mathrm{h}$ on straight track, the noise between 160 $\mathrm{Hz}$ and $1250 \mathrm{~Hz}$ contributed most to the A-weighted interior noise. Noh et al. [15] studied the interior noise characteristics of high-speed trains. They found that, at the speed of $150 \mathrm{~km} / \mathrm{h}$, the spectra of interior noise were dominated by low and mid-frequency components. The highest A-weighted interior noise levels occurred between $500 \mathrm{~Hz}$ and $1250 \mathrm{~Hz}$. At the speed of $300 \mathrm{~km} / \mathrm{h}$ the spectra of interior noise were dominated by low frequencies. Zhang et 
al. [16] investigated the interior noise characteristics of a Chinese high-speed train running on both a slab track and a ballasted track and either at the ground surface or in a tunnel. The results of field tests showed that, when the train ran at $200 \mathrm{~km} / \mathrm{h}$ on slab track, at the different measuring positions the interior noise levels were higher by 0 to $2.5 \mathrm{~dB}(\mathrm{~A})$ than on ballast track. At higher train speeds, the differences in interior noise between the slab track and the ballast track became smaller.

Shi et al [17] predicted the interior noise below $300 \mathrm{~Hz}$ in the cab of a subway train running at $60 \mathrm{~km} / \mathrm{h}$ caused by vibration of the train panels by applying the vehicle-track coupling dynamics as the excitation. Shi et al. [18] also established a vehicle-track coupled dynamic model, a finite element model and an acoustic boundary element model to calculate the noise up to $5000 \mathrm{~Hz}$ in the interior passenger spaces of a high-speed train running at 200 $\mathrm{km} / \mathrm{h}$ caused by track irregularities and ascertained the distribution of the acoustic features. Liu et al [19] calculated the noise below $250 \mathrm{~Hz}$ inside the passenger compartment of a highspeed train at $300 \mathrm{~km} / \mathrm{h}$. In these three papers, the FRA Class 5 irregularity spectrum was adopted as the excitation. Moreover, no comparisons were made with experiments. However, generally the American standard track irregularity spectra are suitable for wavelengths in the range 3-300 $\mathrm{m}$ [20]. For a train speed of $40 \mathrm{~km} / \mathrm{h}$, a wavelength of $3 \mathrm{~m}$ corresponds to an excitation frequency of $3.7 \mathrm{~Hz}$ and even for a speed of $300 \mathrm{~km} / \mathrm{h}$ it is only $28 \mathrm{~Hz}$. Clearly shorter wavelengths are required for noise predictions.

Zhang et al [21] analysed the contributions of interior noise of a high-speed train between $100 \mathrm{~Hz}$ and $3150 \mathrm{~Hz}$ through measurements and simulations based on statistical energy analysis (SEA). They used the model to identify the contributions from different panels and concluded that the noise from the bogie region is an important source. Zheng et al [22] combined various methods including multi-body dynamics, finite element analysis of the carbody and fast multipole boundary elements into a framework based on SEA they called statistical acoustic energy flow (SAEF). They used this to simulate the full-spectrum interior noise of a high-speed train which gave good agreement with measurements but no insight was given into the contributions of different paths or components.

Recent research has also focused on the noise radiation and transmission behaviour of the extruded aluminium panels from which modern rolling stock is often constructed. The sound transmission loss (STL) of such extruded aluminium panels is less satisfactory than flat panels with the same surface density. Xie et al [23] presented an SEA model to predict the vibroacoustic behaviour of aluminium extrusions used in railway vehicles. Kim et al. [24] proposed a prediction method of the STL of the aluminium extruded panel using finite element analysis. Zhang et al. [25] modelled aluminium extrusions using wavenumber finite element and boundary element methods and studied the dependence of the STL on the cross-section geometry. Sui et al. [26] modelled the vibrational responses of the extrusion in the low frequency range and measured the transfer mobility and vibration energy of the panel.

The parameter used in ISO 3381 [27] and GB 14892 [28] to evaluate the interior noise is the A-weighted equivalent continuous sound pressure level. However, the A-weighted sound pressure level has not been found to correlate well with perceived acoustic comfort in rail vehicles [1]. In particular, the influence of low frequency noise on people is underestimated. Eade and Hardy [8] suggested that acceptable levels of interior noise should be specified in terms of Preferred Speech Interference Level or Loudness Level. Furthermore, there are no standardised criteria to evaluate the low frequency noise inside railway vehicles. In contrast, 
in ISO 14837 [29] there are some regulations to measure and predict ground-borne noise caused by rail systems in the frequency range $16 \mathrm{~Hz}$ to $200 \mathrm{~Hz}$.

The aim of this paper is to compare the interior noise in a metro vehicle when running over the same track when fitted with rail fasteners of different stiffness. The approach taken is mainly experimental. In addition to measurements of interior noise, axlebox vibration, train floor vibration, exterior noise and rail vibration have also been measured and are used to investigate the differences further. All these quantities were measured at the same time to avoid the influence of any other changes in the conditions. The measurements are described in Section 2 and the results are discussed in Section 3. Following this, in Section 4, numerical models are used to investigate the reasons for the differences.

\section{Description of the measurements}

\subsection{Test track}

A series of measurements were undertaken at the Comprehensive Rail Transportation Test Line at Jiading campus, Tongji University, China. The test line currently consists of a length of $678 \mathrm{~m}$ of electrified standard gauge track. For the purpose of the current tests a section of slab track of length $28 \mathrm{~m}$ was installed in the test line and fitted with two types of rail fastener. The test section is a straight line.

The two types of fasteners are fitted with a rubber pad and a plastic insulator. The first type (Fastener A) has a static stiffness of 30-35 MN/m (TB/T 3396.3 [30]). The second (Fastener B) has a static stiffness of 10-15 MN/m (EN 13146-9+A1 [31]). These stiffness values correspond to the gradual application of a preload of $70 \mathrm{kN}$ (100 kN for Fastener B) over a period of about a minute. The two types of fasteners were both installed on the same section of track in such a way that each one could be removed during the testing of the other (Fig.1 and Fig. 2). The spacing between fasteners of each type is $0.6 \mathrm{~m}$. The rail roughness was not measured but as the same rails are used for both types of fastener it can be considered to be invariant.

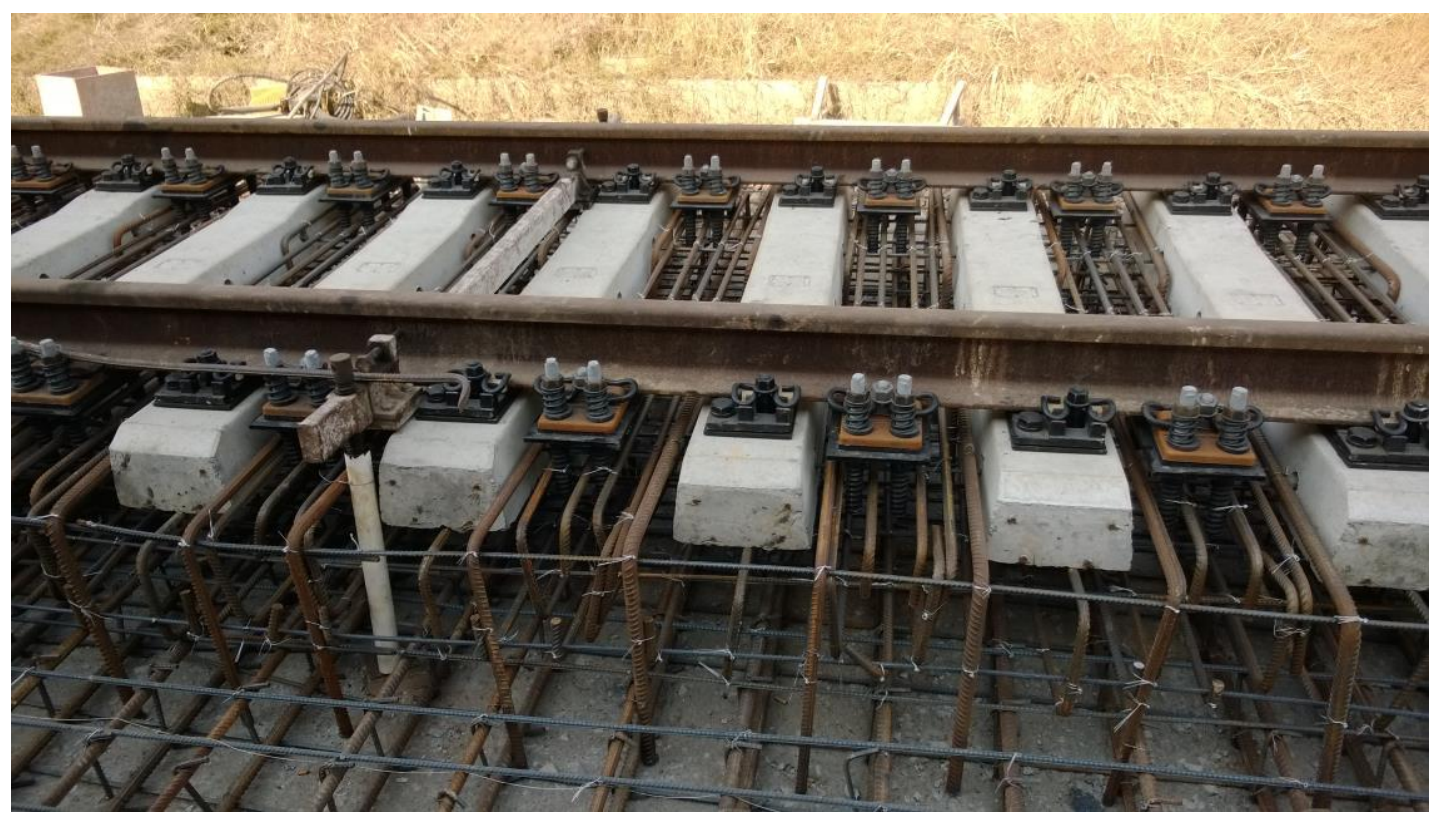

Fig. 1. Test site during construction showing Fastener A attached to the sleepers and Fastener B in between sleepers 


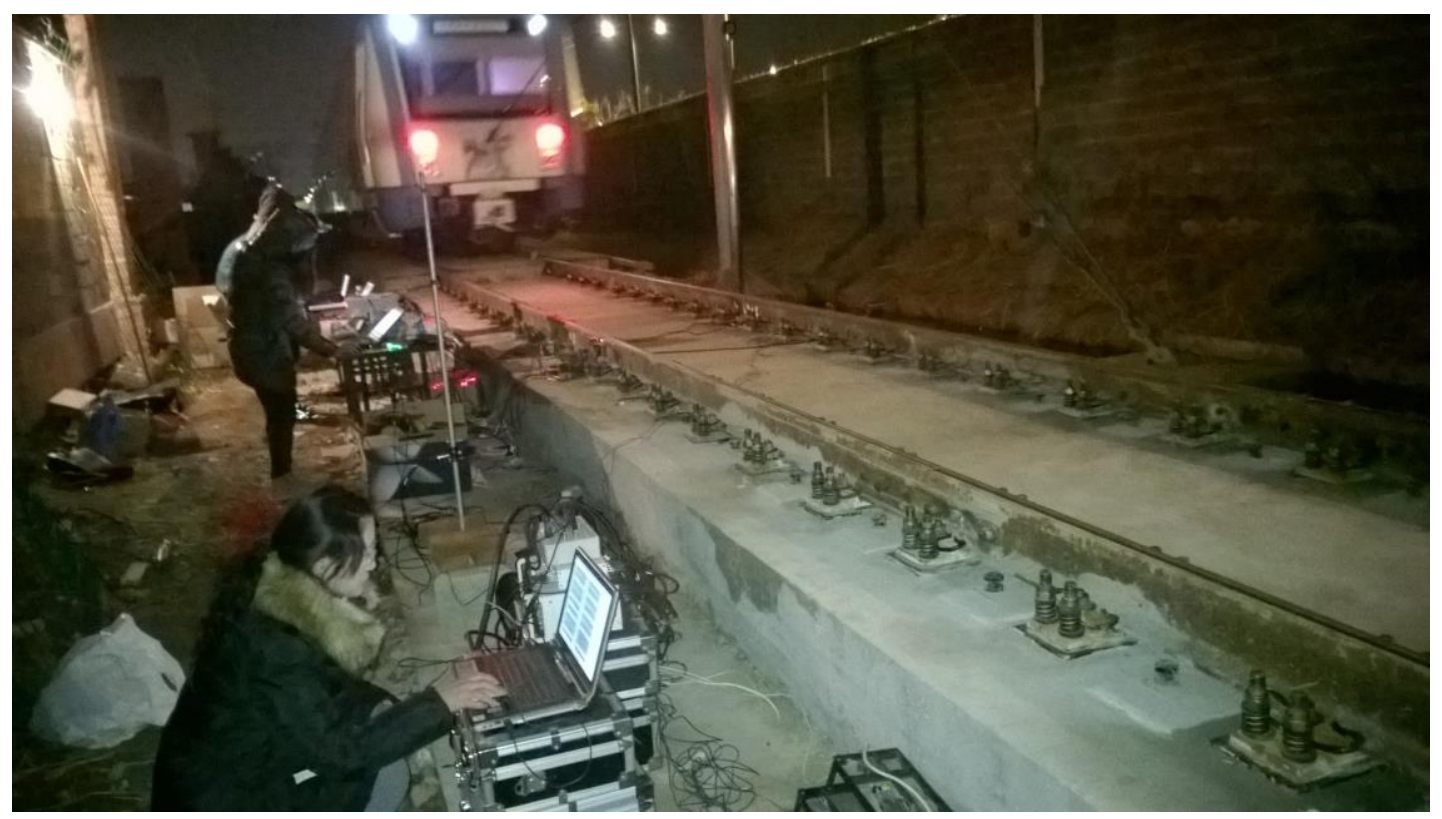

Fig. 2. Test site after construction

\subsection{Train}

The test train consisted of two metro vehicles, a power car and a trailer car, with an axle load of $145 \mathrm{kN}$. The length of each car is $22.4 \mathrm{~m}$. The nominal wheel rolling diameter is 0.84 $\mathrm{m}$. There was no internal decoration or seating. The air conditioning inside the car was switched off for the duration of the tests. The running speeds were 20,30 and $40 \mathrm{~km} / \mathrm{h}$. For each vehicle speed at least four different train passages were measured; the results presented are the average of these multiple train passages.

\subsection{Vibration and noise measurement points layout}

According to the Noise Limit and Measurement for Train of Urban Rail Transit standard (GB 14892) [28] and referring to ISO 3381 [27], six points were used to measure the interior noise, as shown in Fig. 3 and Fig.4. The microphones were located at heights of $1.2 \mathrm{~m}$ and $1.6 \mathrm{~m}$ above the vehicle floor along the centreline of the trailer car. M1 and M2 were close to the driver's cab and located in the central axis of the side doors. M3 and M4 were in the centre of the car, also opposite side doors. M5 and M6 were close to the connection between the two cars and were located directly above the bogie. Three accelerometers (V1, V2 and V3) were installed on the floor of the same vehicle directly below the noise measurement points (see Fig. 3 and Fig. 4).

Beside the track, two microphones were used to measure the exterior noise (Fig. 5 and Fig. 6). These were located at $2.0 \mathrm{~m}$ from the track centreline at the same height as the top of the rail $(\mathrm{P} 1)$, and at $7.5 \mathrm{~m}$ from the track centreline and $3.5 \mathrm{~m}$ above the rail head (P2). Due to various objects, including a wall, the environment did not correspond to a free field.

Two accelerometers were used to measure the vertical vibration of the axlebox (Fig. 7 shows one of them). Six accelerometers were used to measure the vertical vibration of the track, as shown in Fig.8. Accelerometers A1 and A2 are located on the rail foot; the others are located on the slab or the ground surface but are not used here. 


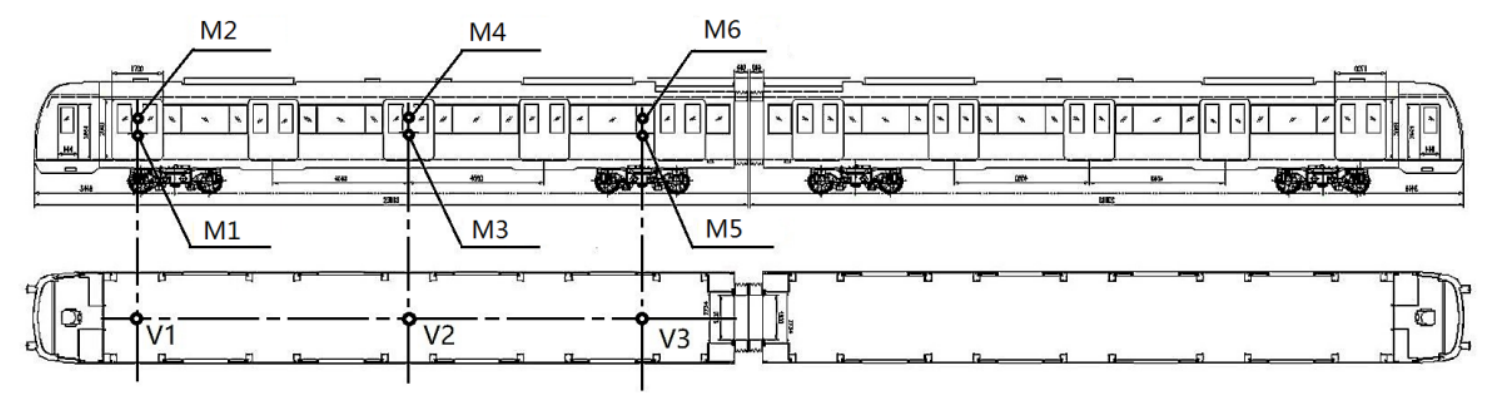

Fig. 3. Layout of the interior vibration and noise measurement points
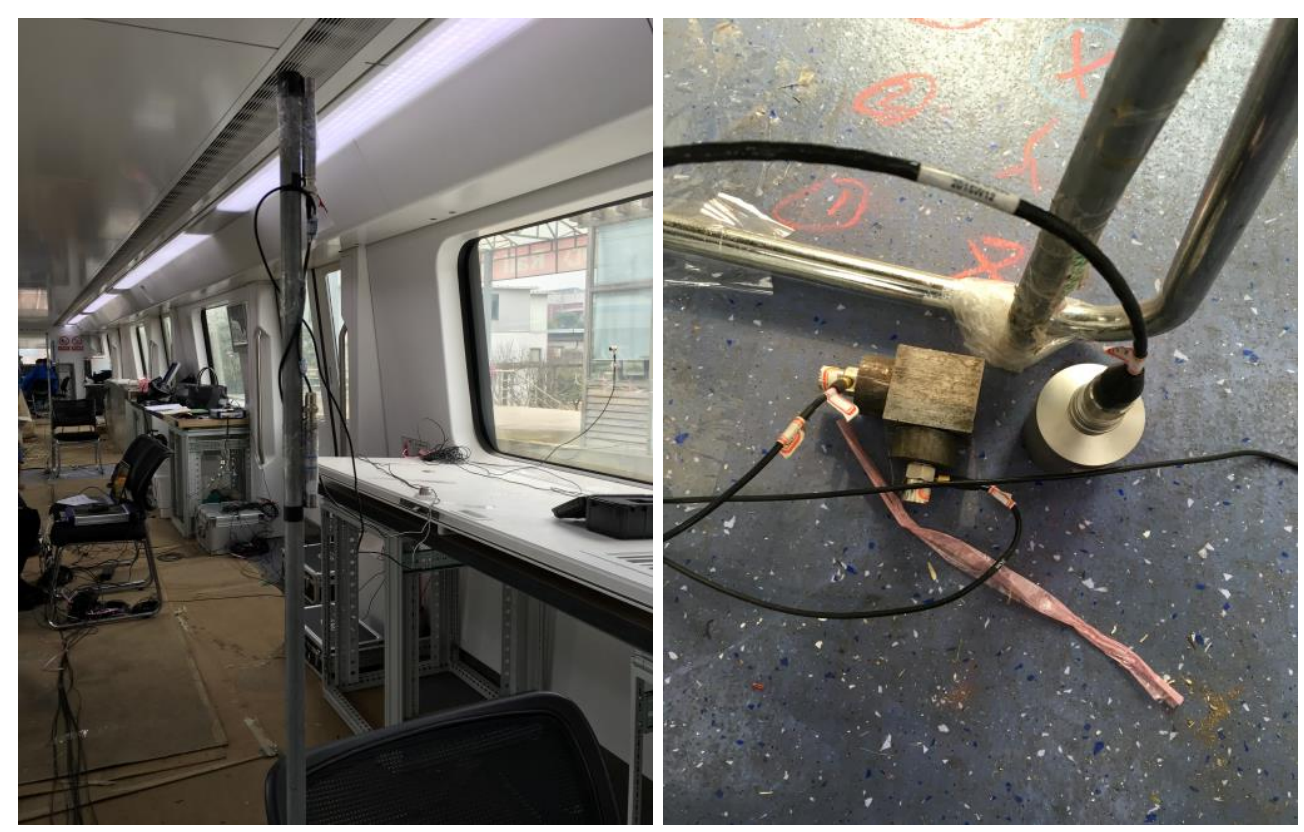

Fig. 4. Photograph of instrumentation in the vehicle

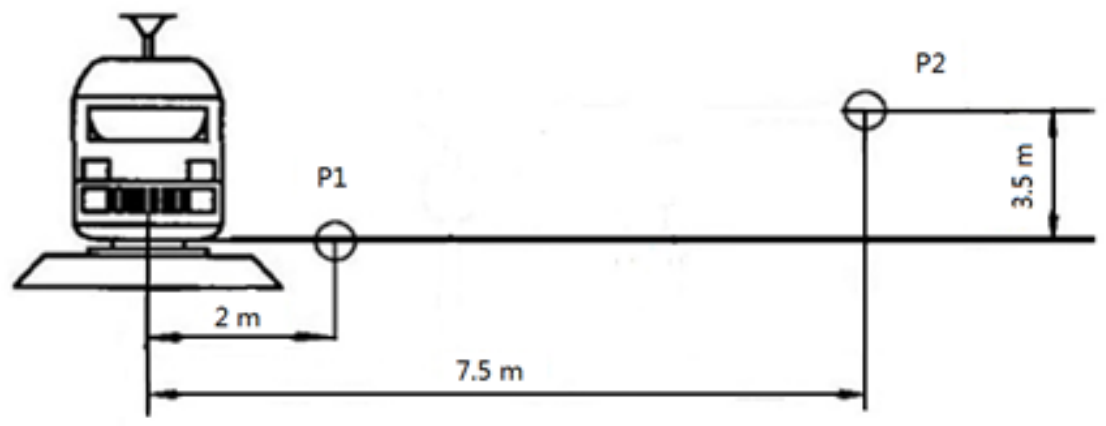

Fig. 5. Exterior noise measurement points 


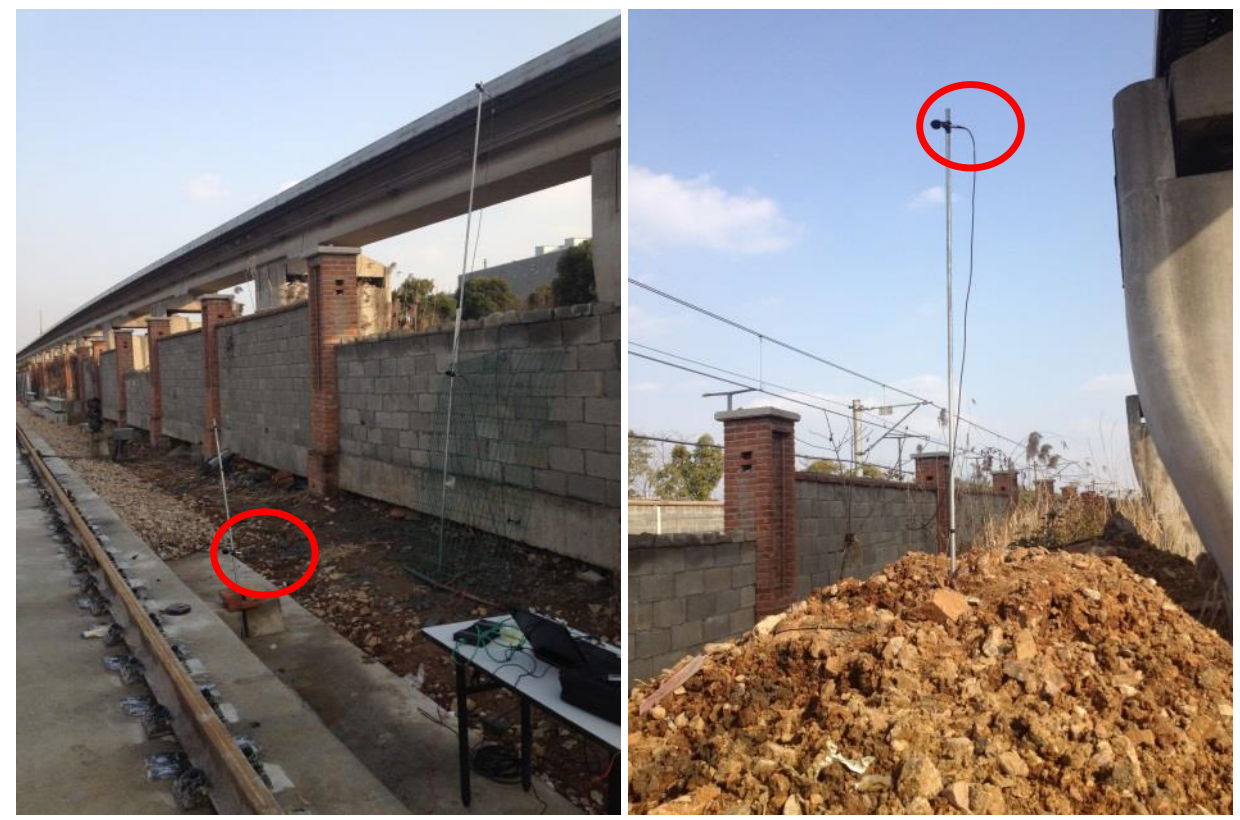

Fig. 6. Photograph of exterior noise measurement

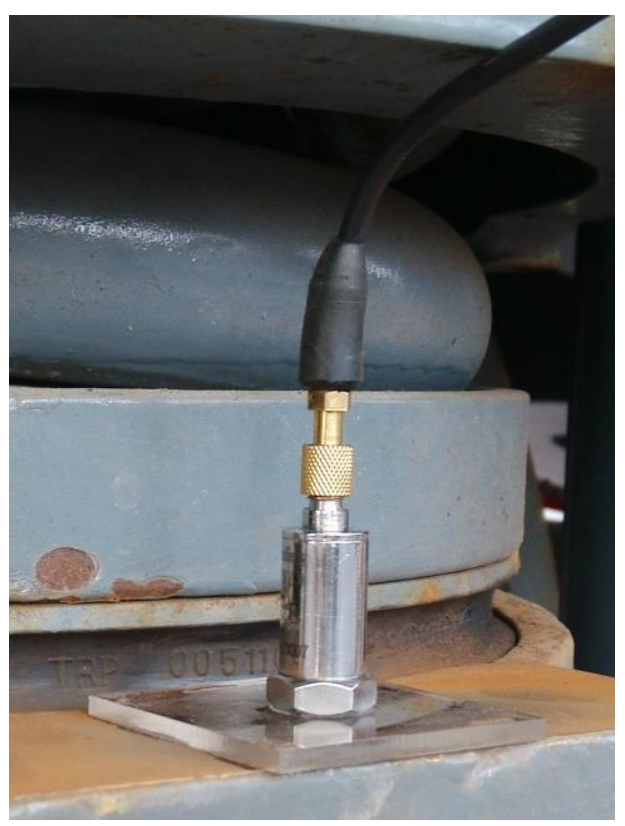

Fig.7. Measurement point for vertical vibration of axlebox

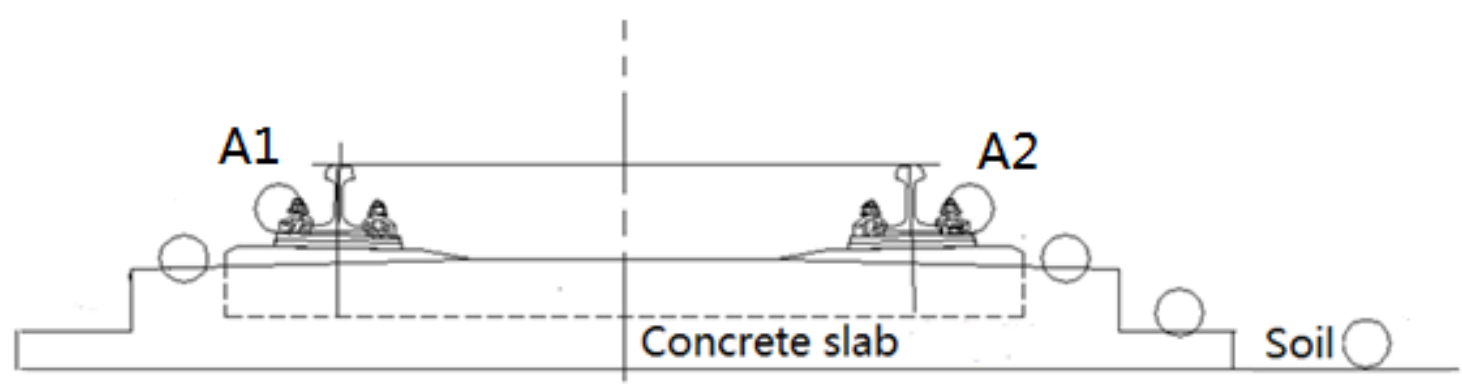

Fig. 8. Location of accelerometers on the track 


\section{Measurement Results}

\subsection{Interior noise spectra}

During the field measurements, at least four train passages were measured for each vehicle speed. It was ensured that the maximum difference between the results for a given condition was less than $3 \mathrm{~dB}$, otherwise the measurement was repeated. The microphones calibrated using a sound level calibrator before and after testing; the deviation between the calibration before and after the tests was less than $0.5 \mathrm{~dB}$. To illustrate typical signal-tonoise ratios, Fig. 9 shows the average interior noise for Fastener B at Point M5 at $20 \mathrm{~km} / \mathrm{h}$ and $40 \mathrm{~km} / \mathrm{h}$, together with the background noise. The differences between the signal and the background noise are greater than $10 \mathrm{~dB}$ over most of the frequency range. Only at 50 $\mathrm{Hz}$ and $63 \mathrm{~Hz}$ are the differences smaller than this $(4.1 \mathrm{~dB}$ at $50 \mathrm{~Hz}, 6.6 \mathrm{~dB}$ at $63 \mathrm{~Hz}$ and also $8.9 \mathrm{~dB}$ at $5000 \mathrm{~Hz}$ for $20 \mathrm{~km} / \mathrm{h} ; 6.2 \mathrm{~dB}$ at $50 \mathrm{~Hz}$ and $8.8 \mathrm{~dB}$ at $63 \mathrm{~Hz}$ for $40 \mathrm{~km} / \mathrm{h}$ ).

Fig.10 shows the linear (i.e. unweighted) sound pressure level in $1 / 3$ octave bands at different interior measurement points for the two fastener systems. It can be seen that the spectra are dominated by the noise in the low frequency range. There is a broad peak between 125 and $200 \mathrm{~Hz}$, which is larger at Points M1 and M5 than in the centre of the car at Point M3.

Fig.11 and Fig.12 show the dependence of the sound pressure levels on train speed. At low frequencies these results are nearly independent of speed, but above $250 \mathrm{~Hz}$ the sound level increases with increasing speed by up to $9 \mathrm{~dB}$ for a doubling of speed, which is typical of rolling noise [5].

Fig.13 shows the level difference between the results for Fastener $B$ and Fastener $A$ at two measurement points. Lines are shown for all three speeds. In the frequency range 315 to $1000 \mathrm{~Hz}$, the noise levels are higher for Fastener B, with an average level difference of 3 $\mathrm{dB}$. Also at 100-125 Hz Fastener B has a higher noise level than Fastener A. At other frequencies the level difference is smaller and in some cases. Fastener $A$ shows higher noise levels than Fastener B, in particular at $63 \mathrm{~Hz}$ and $125-200 \mathrm{~Hz}$, the latter corresponding to the peak in the spectra in Figs 9-11.

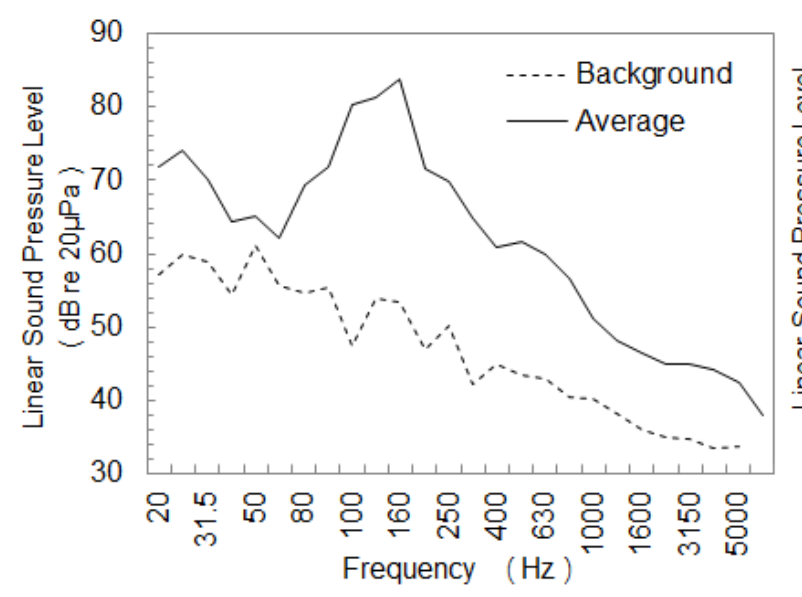

(a)

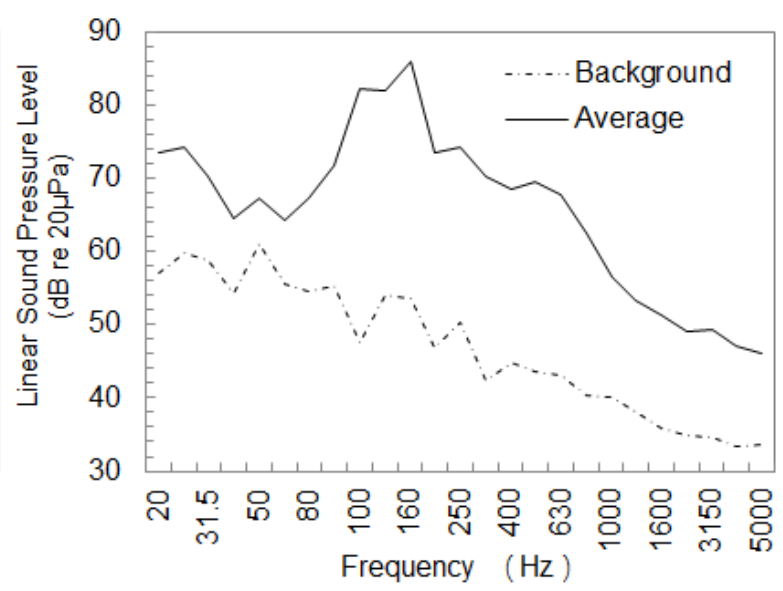

(b)

Fig. 9. Average interior noise spectra of Fastener B with background. (a) $20 \mathrm{~km} / \mathrm{h}$; (b) $40 \mathrm{~km} / \mathrm{h}$ 


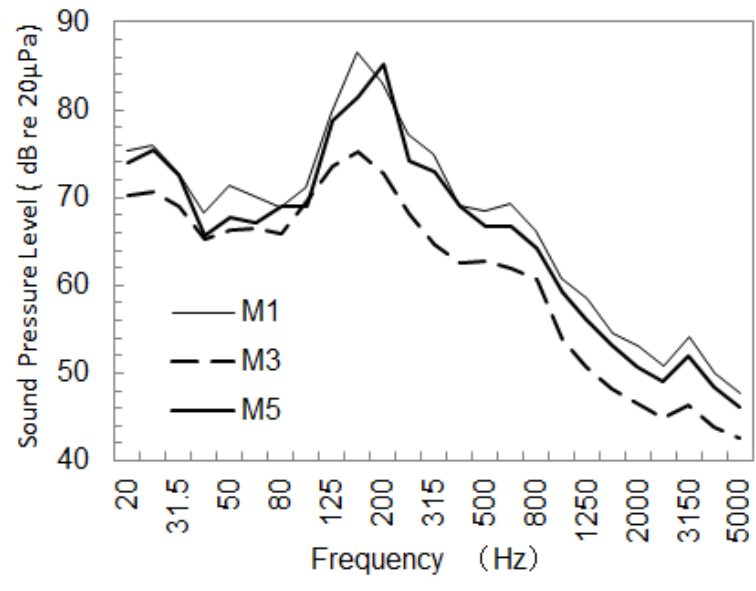

(a)

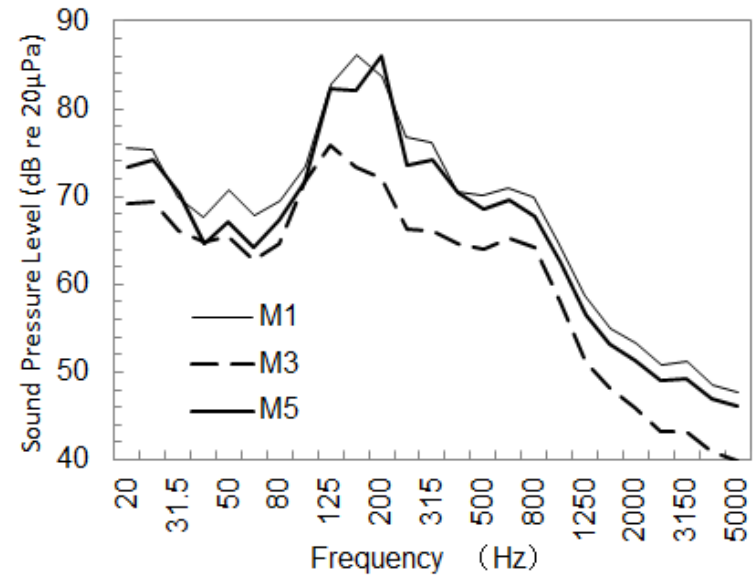

(b)

Fig. 10. Interior noise spectra at $M 1, M 3, M 5$ at $40 \mathrm{~km} / \mathrm{h}$. (a) Fastener $A$; (b) Fastener $B$

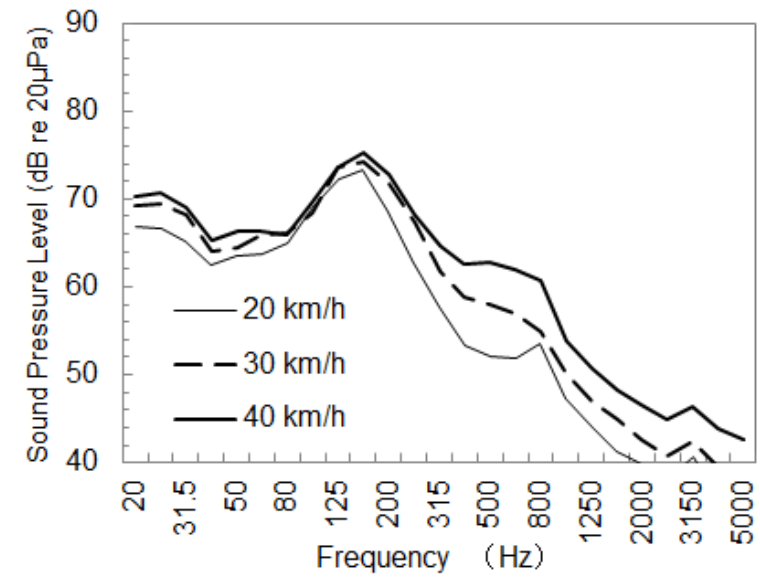

(a)

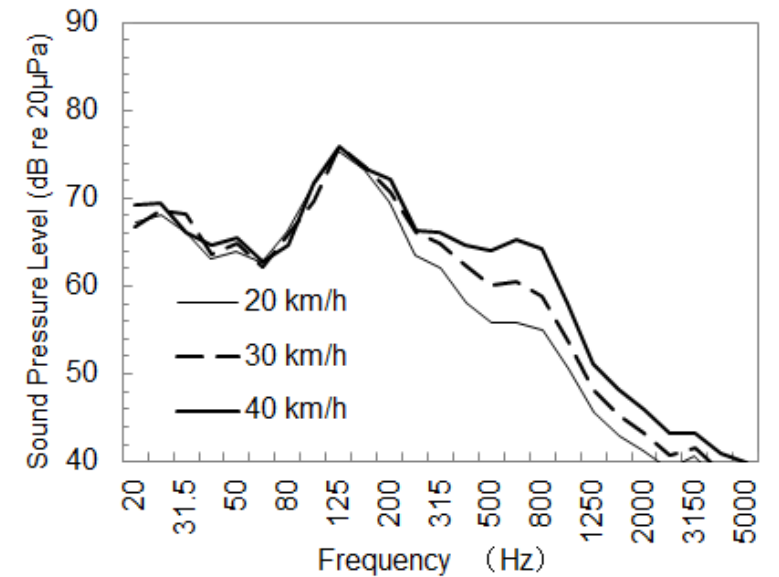

(b)

Fig. 11. Interior noise spectra at $M 3$ at 20, 30, 40 km/h. (a) Fastener A; (b) Fastener B

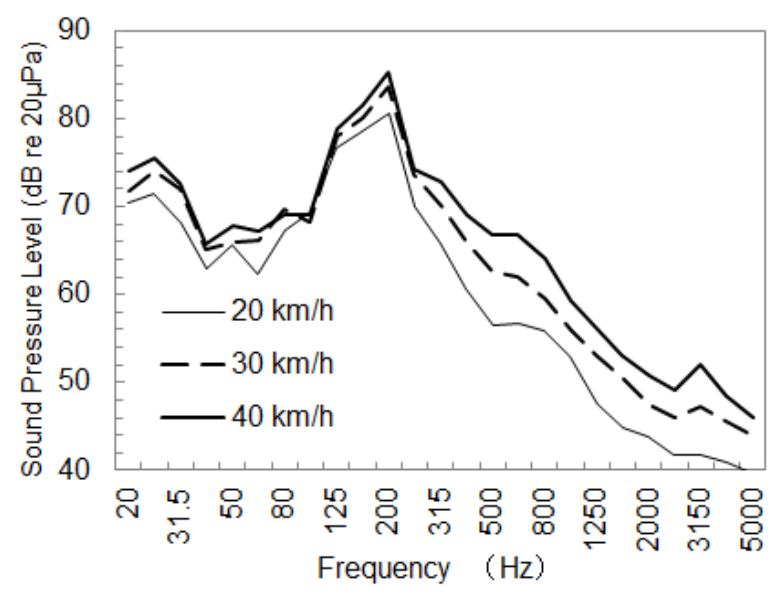

(a)

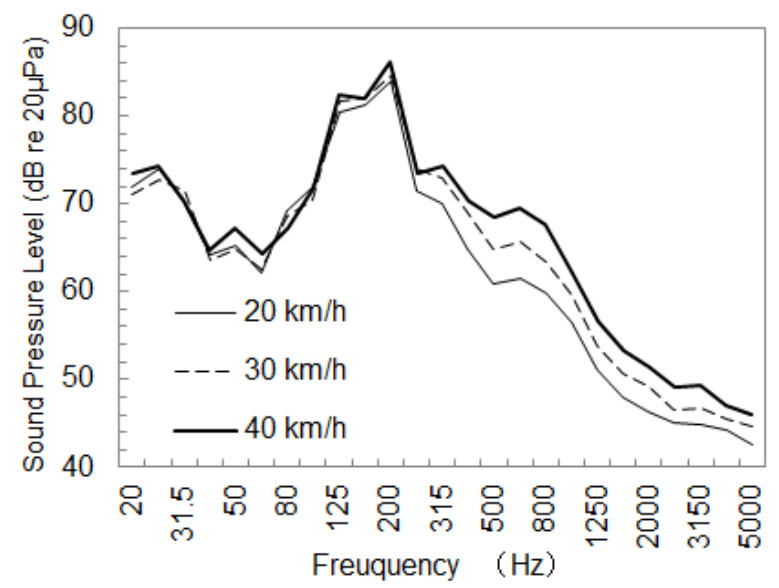

(b)

Fig. 12. Interior noise spectra at $M 5$ at 20, 30, 40 km/h. (a) Fastener A; (b) Fastener B 


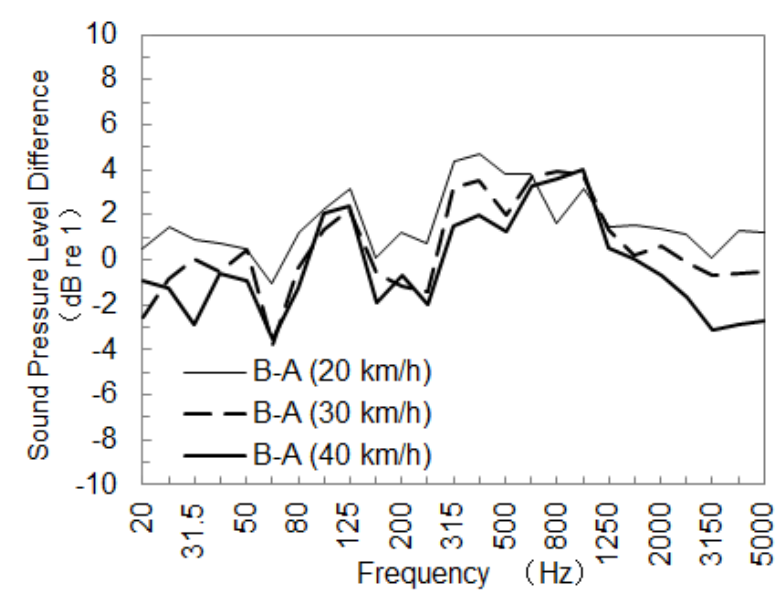

(a)

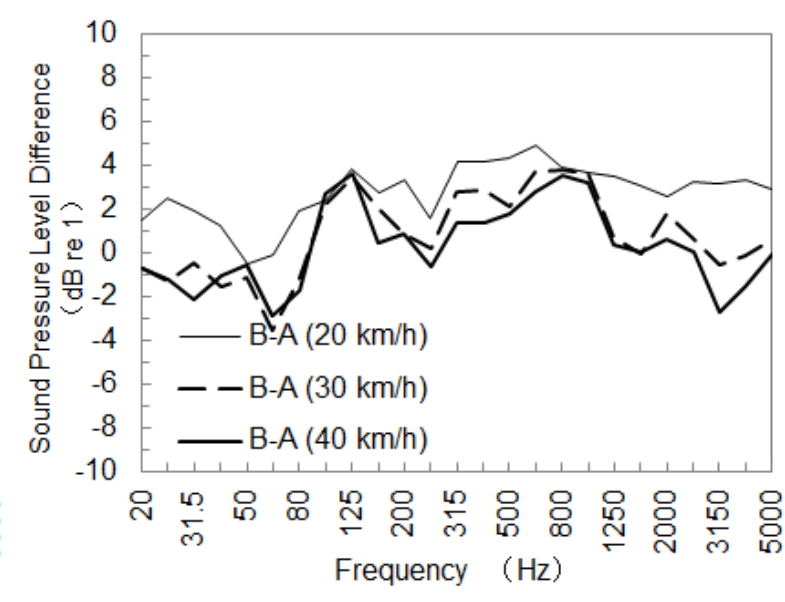

(b)

Fig. 13. Difference in interior noise spectra: Fastener $B$ minus $A ;(a)$ at $M 3$ and (b) at M5

\subsection{A weighted total linear sound pressure level}

The total sound pressure level is a simple and direct parameter to quantify the sound level. Although the A-weighted level has some limitations, it is still the quantity specified in the standards $[27,28]$ so it is used here to summarise the differences between fastener systems.

Table 1 Total sound pressure level within the train ( $\mathrm{dB}(\mathrm{A})$ re $20 \mu \mathrm{Pa})$

\begin{tabular}{cccccccc}
\hline Speed & Classification & M1 & M2 & M3 & M4 & M5 & M6 \\
\hline \multirow{3}{*}{$20 \mathrm{~km} / \mathrm{h}$} & Fastener A & 74.3 & 71.6 & 65.8 & 65.8 & 73.1 & 69.1 \\
& Fastener B & 76.9 & 74.3 & 66.8 & 66.8 & 75.9 & 71.7 \\
& Difference & 2.6 & 2.7 & 1.0 & 1.0 & 2.8 & 2.6 \\
\hline \multirow{3}{*}{$30 \mathrm{~km} / \mathrm{h}$} & Fastener A & 76.5 & 74.0 & 67.6 & 67.5 & 75.6 & 71.7 \\
& Fastener B & 78.4 & 75.9 & 68.7 & 68.7 & 77.3 & 73.7 \\
& Difference & 1.9 & 1.9 & 1.1 & 1.2 & 1.7 & 2.0 \\
\hline \multirow{3}{*}{$40 \mathrm{~km} / \mathrm{h}$} & Fastener A & 79.0 & 76.5 & 70.2 & 70.2 & 77.9 & 74.2 \\
& Fastener B & 80.1 & 77.5 & 71.8 & 71.6 & 79.3 & 75.9 \\
& Difference & 1.2 & 1.0 & 1.6 & 1.4 & 1.4 & 1.7 \\
\hline
\end{tabular}

The test results under different running speeds are shown in Table 1. In general, when using the softer Fastener B, the noise levels are greater than those with Fastener A. As the running speed increases, the difference between the two fasteners mostly becomes smaller. Because positions M1, M2, M5 and M6 are above a bogie, they are likely to be more influenced by structure-borne noise transmitted from the bogie. Conversely positions M3 and M4 are near the centre of the vehicle and will be more influenced by airborne sound. However, from Fig. 12 these positions all show similar trends.

\subsection{Vibration spectra of the vehicle floor}

The vibration measured on the car floor at $40 \mathrm{~km} / \mathrm{h}$ is shown in Fig.14 and Fig.15. Fig.14 shows the vertical vibration at the point V2 in middle of the car, while Fig.15 shows the vertical vibration at V3 above the bogie. The level difference between the results for the two fasteners is shown in Fig. 16. From this it can be seen that, in the frequency range 250 to $1250 \mathrm{~Hz}$, the vibration level at V2 is larger for Fastener B, with an average level difference of $1.5 \mathrm{~dB}$. For position $\mathrm{V} 3$ above the bogie Fastener $\mathrm{B}$ gives a higher vibration level with an average difference of $2.2 \mathrm{~dB}$ than Fastener A for all frequencies above $80 \mathrm{~Hz}$. 


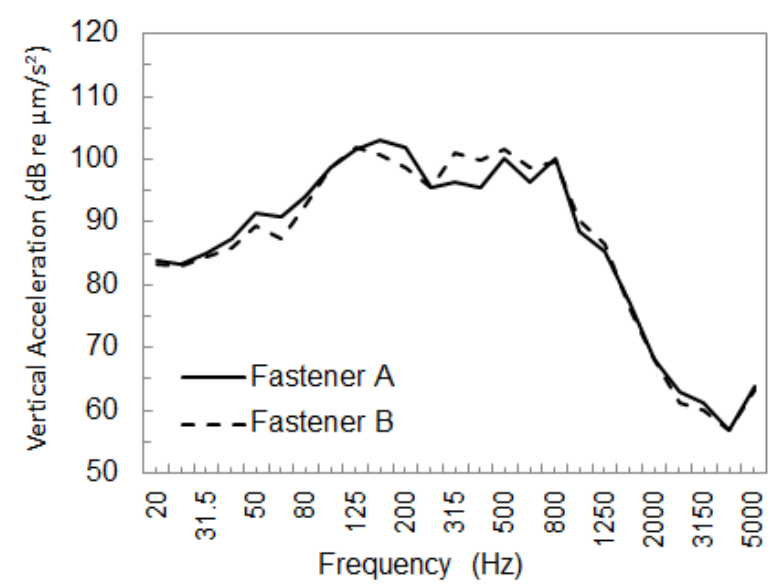

Fig. 14. Floor vibration at V2.

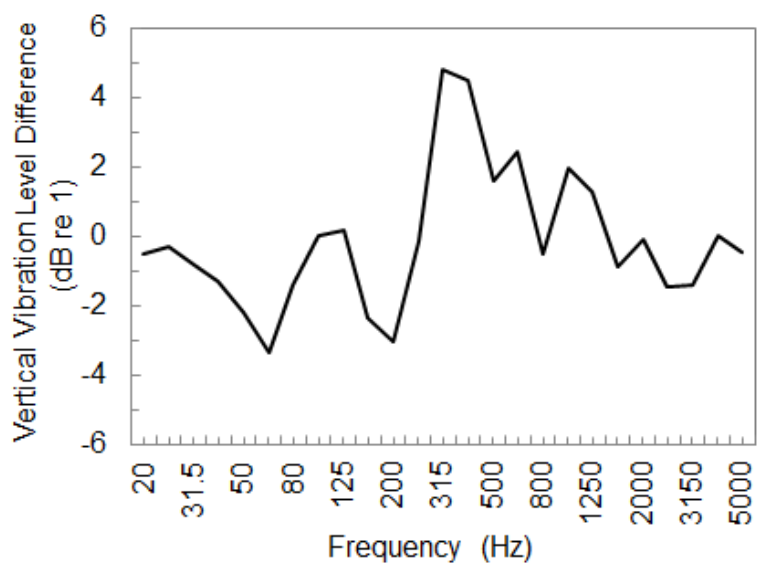

(a)

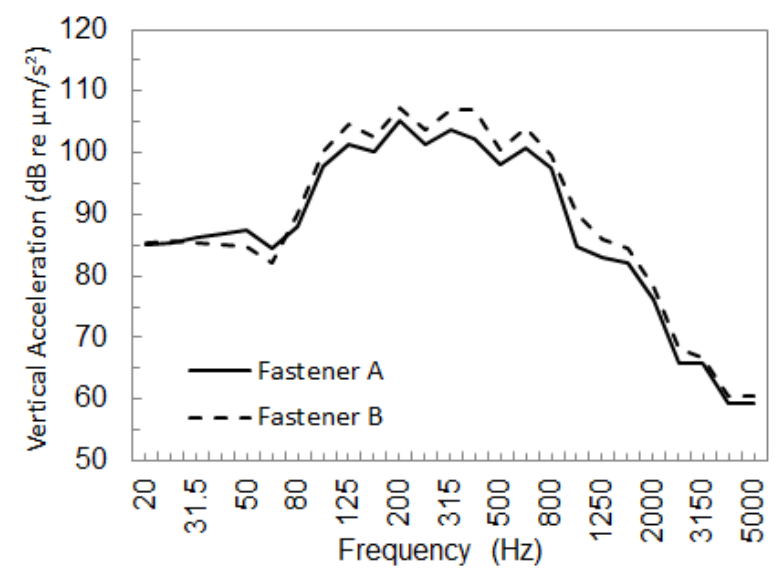

Fig. 15. Floor vibration at V3.

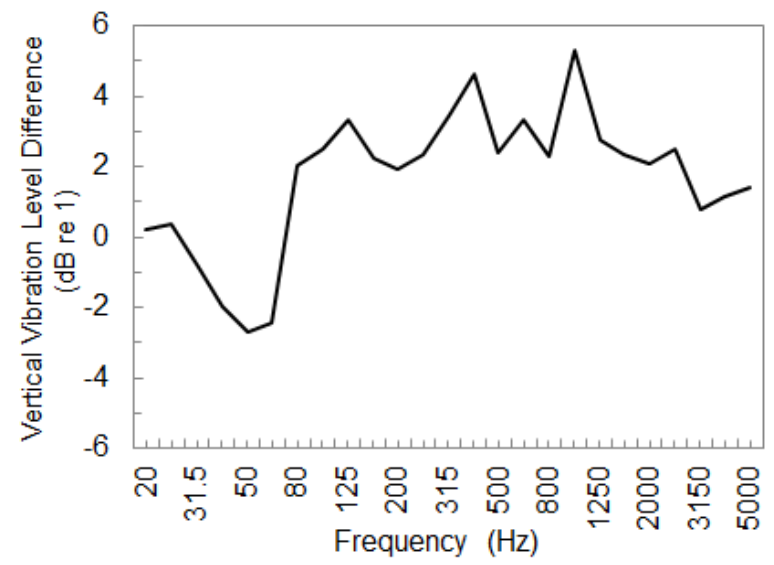

(b)

Fig. 16. Vibration of Fastener B minus $A$; (a) at V2; (b) at V3

\subsection{Vibration spectra of axlebox}

Figure 17 shows the acceleration of the axlebox at $40 \mathrm{~km} / \mathrm{h}$. In the low frequency range up to $250 \mathrm{~Hz}$ the vibration for Fastener A is generally greater than for Fastener B, whereas at higher frequencies this is reversed. This should be a direct indicator of differences in structure-borne transmission.

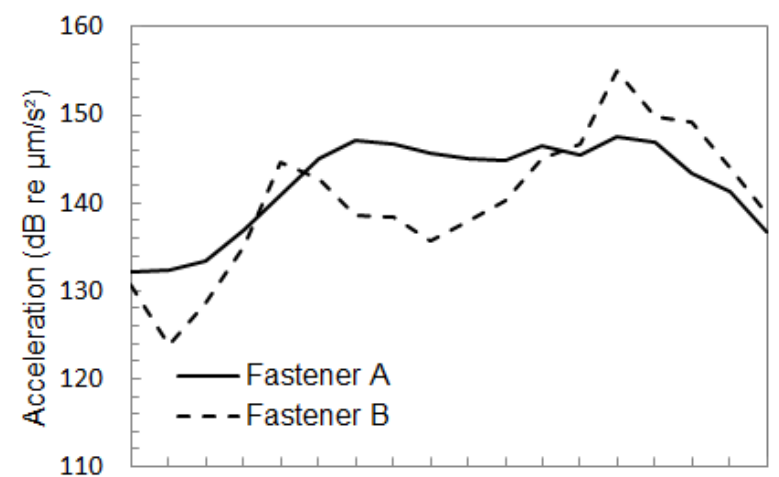

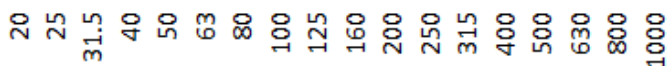
Frequency $(\mathrm{Hz})$

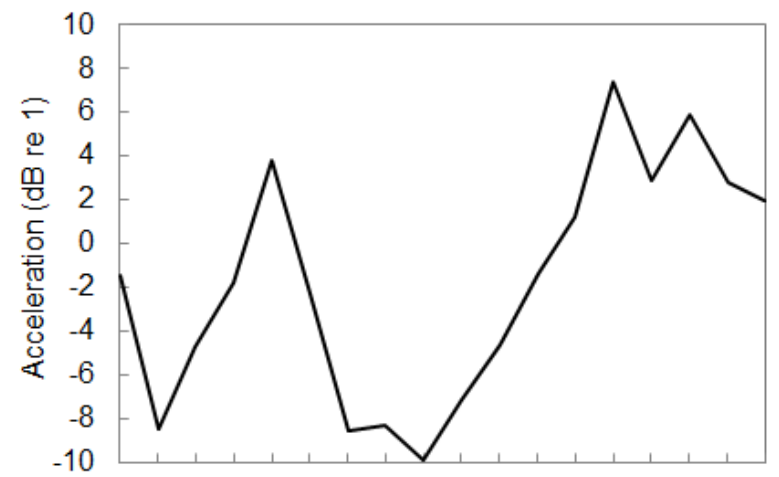

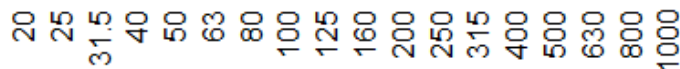
Frequency $(\mathrm{Hz})$ 
Fig. 17. Vertical acceleration of axlebox. (a) $1 / 3$ octave band spectrum; (b) Fastener B minus A

\subsection{Exterior noise and vibration spectra}

Besides the structure-borne noise transmission, the interior noise is also the result of airborne transmission from outside, in particular from rolling noise. Fig. 18 shows the linear sound pressure level measured at the exterior microphone positions P1 and P2 during the passage of the train at $40 \mathrm{~km} / \mathrm{h}$. These microphone positions were shown in Fig. 5 . The level difference between the two fasteners is shown in Fig. 19. Similar level differences are seen for the two microphone positions. As can be seen in Fig. 18 and 19, the noise with Fastener $B$ is greater than that for Fastener A between $160 \mathrm{~Hz}$ and $500 \mathrm{~Hz}$ by up to $2.6 \mathrm{~dB}$, but the noise from Fastener $\mathrm{A}$ is greater for frequencies above and below this range.

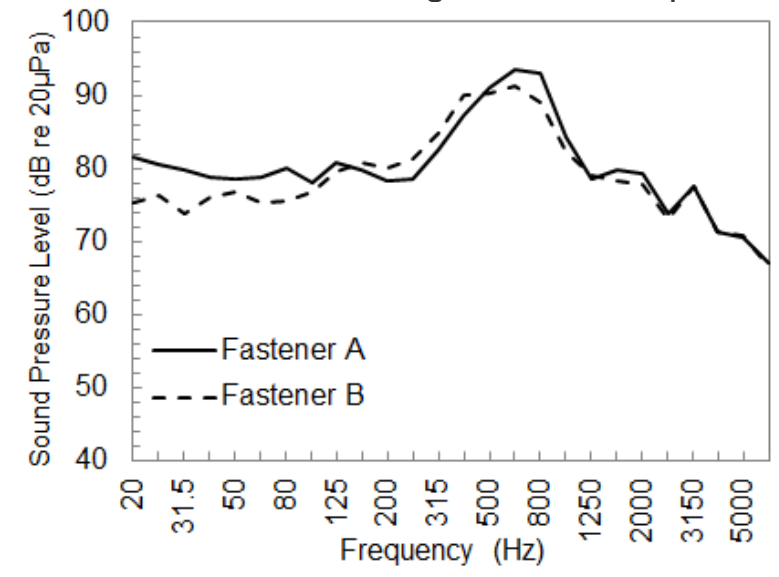

(a)

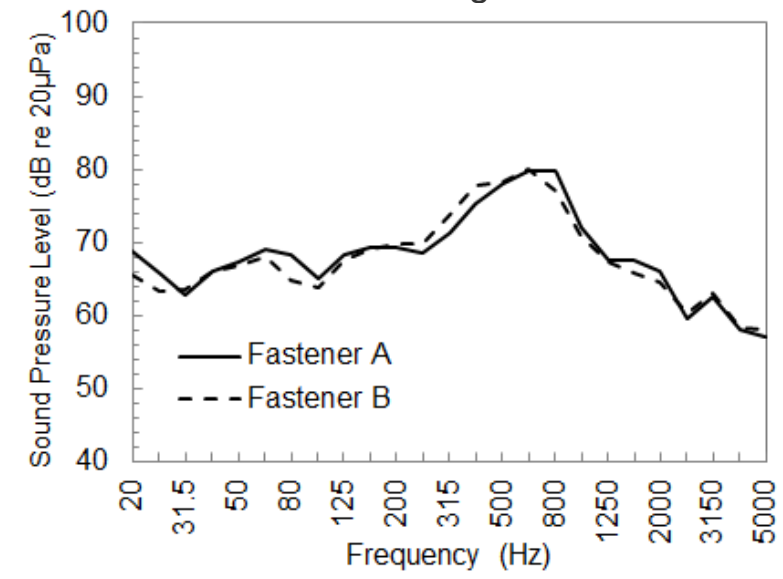

(b)

Fig. 18 Exterior noise: (a) at P1 and (b) at P2.

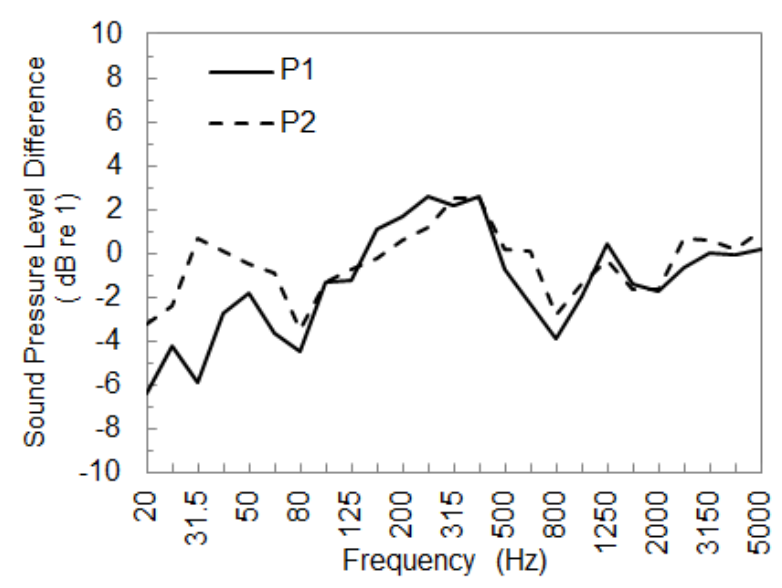

Fig. 19. Exterior noise of Fastener $B$ minus Fastener $A$ at $P 1$ and $P 2$ 


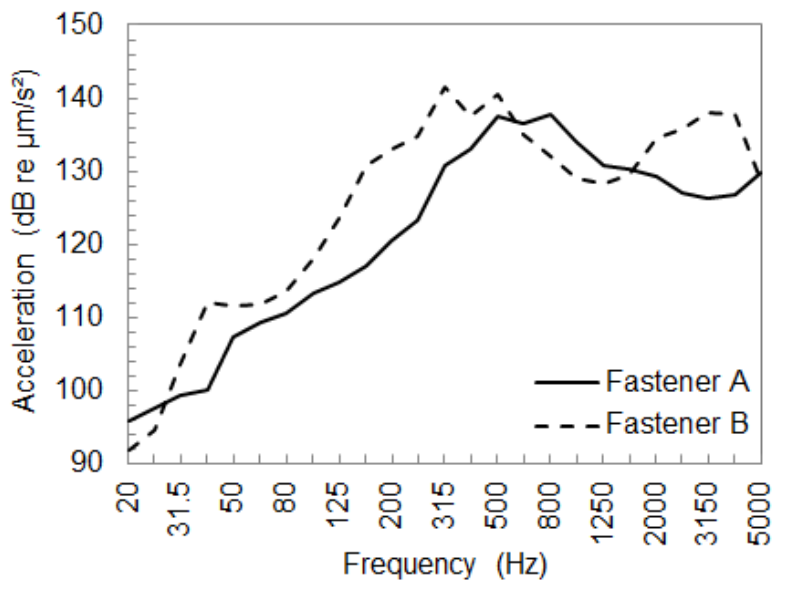

(a)

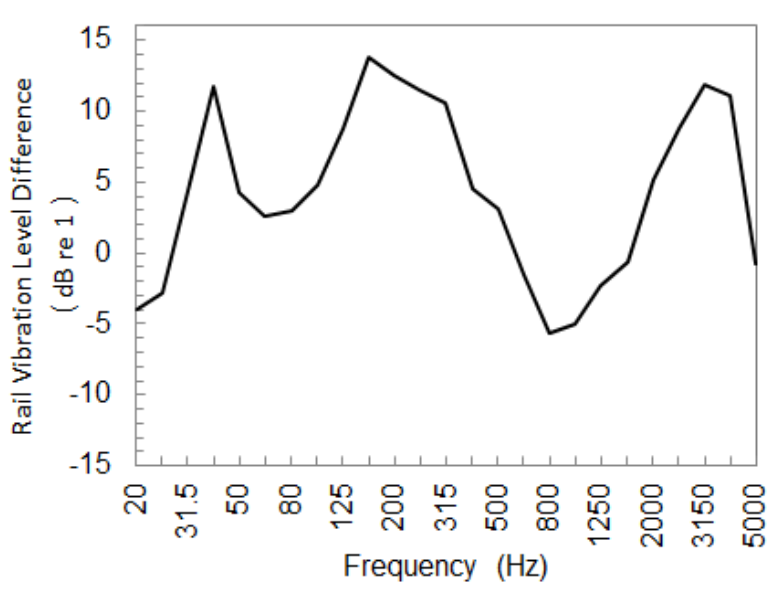

(b)

Fig. 20. Rail vibration. (a) $1 / 3$ octave band spectrum; (b) Fastener B minus $A$

Figure 20 shows the vertical rail vibration during train passages at $40 \mathrm{~km} / \mathrm{h}$. The vibration with Fastener $\mathrm{B}$ is larger than that for Fastener $\mathrm{A}$ below $500 \mathrm{~Hz}$ and also at high frequency, but between 500 and $1600 \mathrm{~Hz}$ the vibration is greater for Fastener A.

\section{Comparison with theoretical model}

To give insight into the effect of the fastener stiffness on interior noise and to provide some interpretation of the experimental results, it is useful to make comparisons with theoretical models. However, a comprehensive model of the airborne and structure-borne noise transmission into the vehicle interior would require validated sub-models of all components [21, 22]. These include the wheelset, bogie frame, carbody structure and interior acoustics. Moreover, the suspension system elements, including springs, dampers and other connections in both primary and secondary suspension, are critical to the structure-borne transmission and would require detailed validated models.

By focusing only on the relative differences between the two fastener systems, it is possible to use a simplified approach. The differences in the structure-borne noise component will be directly related to the corresponding differences in the axlebox vibration, whereas the differences in airborne noise component will be related to the differences in exterior rolling noise.

In this section comparisons are made with models of the wheel/track interaction contained within the TWINS model [32]. Although some of the input parameters are unknown, by using plausible values it can be explored whether the measured differences are consistent with the model.

\subsection{Track dynamics}

The most important track dynamic properties are the vertical point mobility (velocity for a unit force) and the track decay rate. To estimate these, the parameters listed in Table 2 are used for the track with the two fastener systems. The dynamic stiffness values are assumed to be a factor of 2 larger than the static stiffness values quoted in Section 2.1 above. In addition, a second layer of stiffness is included in Fastener $B$ to represent the upper pad above the metal baseplate. For this fastener an intermediate mass is also included between 
the two elastic layers. The loss factors are chosen based on previous experience and to some extent to improve the fit with the measurements as seen below.

Table 2. Assumed track parameters

\begin{tabular}{lcc}
\hline Rail & Fastener A & Fastener B \\
\hline Vertical bending stiffness $\left(\mathrm{MNm}^{2}\right)$ & 6.42 & 6.42 \\
Rail mass per length $(\mathrm{kg} / \mathrm{m})$ & 60 & 60 \\
Rail shear coefficient & 0.4 & 0.4 \\
Rail loss factor & 0.02 & 0.02 \\
\hline Upper pad & & \\
\hline Pad vertical stiffness $(\mathrm{MN} / \mathrm{m})$ & - & 120 \\
Pad vertical loss factor & - & 0.35 \\
Baseplate parameters & - & 6.0 \\
\hline Baseplate mass $(\mathrm{kg})$ & 0.6 & 0.6 \\
Fastener spacing $(\mathrm{m})$ & & 30 \\
\hline Lower pad & 70 & 0.15 \\
\hline Pad vertical stiffness $(\mathrm{MN} / \mathrm{m})$ & 0.25 & \\
\hline Pad vertical loss factor & &
\end{tabular}

Based on the parameters in Table 2, the point mobility is calculated using a model of a Timoshenko beam continuously supported on one or two elastic layers [5]. The results are shown in Figure 21(a). At low frequencies Fastener B has a higher mobility than Fastener A, reflecting its lower stiffness. For both tracks the mobility has a resonance at which the rail mass bounces on the support stiffness. This occurs at around $220 \mathrm{~Hz}$ for Fastener $\mathrm{A}$ and $120 \mathrm{~Hz}$ for Fastener B. Above this frequency free waves start to propagate in the rail and the mobility tends to that of an infinite beam. A second peak occurs for Fastener B at around $900 \mathrm{~Hz}$ associated with the second layer of resilience. Above $1 \mathrm{kHz}$ the response is dominated by the rail itself so no differences are found between the two fasteners.

The same model can be used to predict the track decay rates, which are important for rolling noise: a low track decay rate corresponds to a high noise level [5]. These are shown in Figure 21(b). The decay rate can be seen to fall from an initial value around $10 \mathrm{~dB} / \mathrm{m}$ above the resonance frequencies identified above. For Fastener $\mathrm{B}$ a second peak in the decay rate occurs around $900 \mathrm{~Hz}$ due to the internal resonance of the baseplate mass between the two layers of stiffness. 
(a)

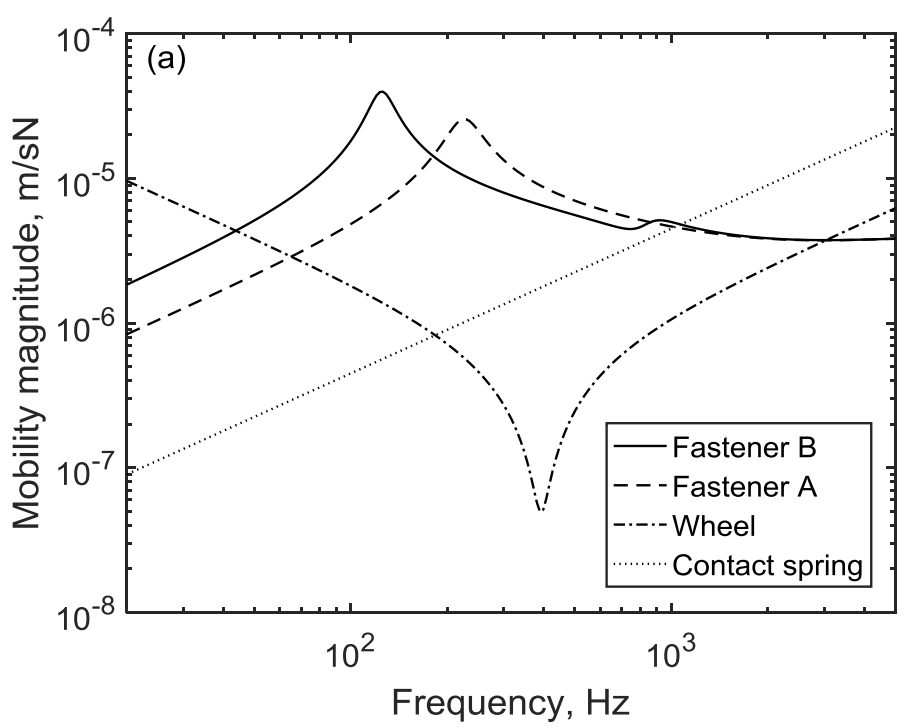

(b)

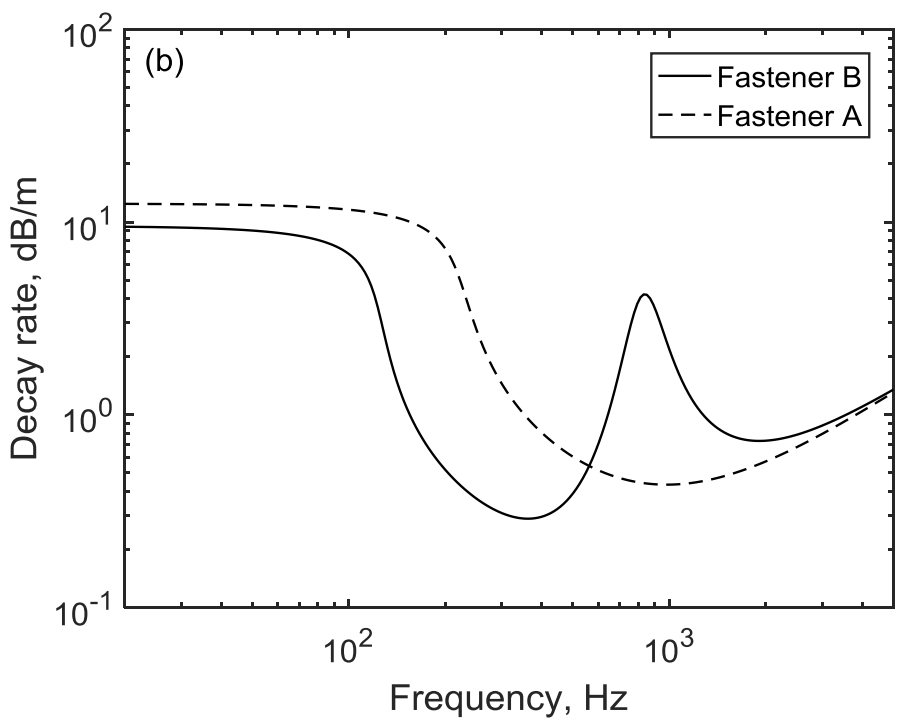

Fig. 21. (a) Estimates of track mobility; the wheel mobility and contact spring mobility are also shown. (b) Track decay rates for the two rail fasteners.

\subsection{Axlebox vibration}

The wheel/track interaction force $F$ at circular frequency $\omega$ can be estimated using the following equation [5]:

$$
F=\frac{\mathrm{i} \omega r}{Y_{r}+Y_{w}+Y_{c}}
$$

where $Y_{r}$ is the rail mobility, $Y_{w}$ is the wheel mobility, $Y_{c}$ is the mobility of the Hertzian contact spring and $r$ is the roughness amplitude. The rail mobility has been obtained in the previous section. For the vertical wheel mobility, a simple model is used representing the wheel by a mass, $m$, in series with a stiffness, $K_{w}[5]$ :

$$
Y_{w}=\frac{1}{\mathrm{i} \omega m}+\frac{\mathrm{i} \omega}{K_{w}}
$$


Although this does not capture the high frequency modes of the wheel, it gives a reasonable representation of the point mobility for frequencies up to $1 \mathrm{k} \mathrm{Hz}$ [2]. For the value of $m$, half the wheelset mass is used, i.e. $827 \mathrm{~kg}$. The stiffness is set to $5 \mathrm{GN} / \mathrm{m}$ with a loss factor of 0.1 . The mobility is also shown in Figure 21(a).

The Hertzian contact stiffness $k_{H}$ is taken as $1.28 \mathrm{GN} / \mathrm{m}$ and gives the following mobility, also shown in Fig. 21(a),

$$
Y_{c}=\frac{\mathrm{i} \omega}{k_{H}}
$$

The axlebox vibration can be estimated by multiplying the contact force (Eq. (1)) by the wheelset mobility (Eq. (2)). The predicted axlebox vibration for a unit roughness is shown in Fig. 22(a). A peak occurs at low frequency which is the resonance of the wheelset mass bouncing on the track stiffness. This resonance can also be identified as the frequency at which the wheelset and track mobilities have equal magnitude, see Fig. 21. It shifts to a lower frequency when a softer rail fastener is used. The difference in axlebox vibration between the two fastener systems is also shown in Fig. 22(b) and compared with the measurements. These show similar trends, with Fastener B giving a lower vibration than Fastener A between about $50 \mathrm{~Hz}$ and $200 \mathrm{~Hz}$ in the predicted results; in the measurements the difference is not quite as large but extends to $400 \mathrm{~Hz}$. Considering the simple model of the wheelset used here this level of agreement is acceptable and can be used to explain the trends seen in the measurements.

(a)

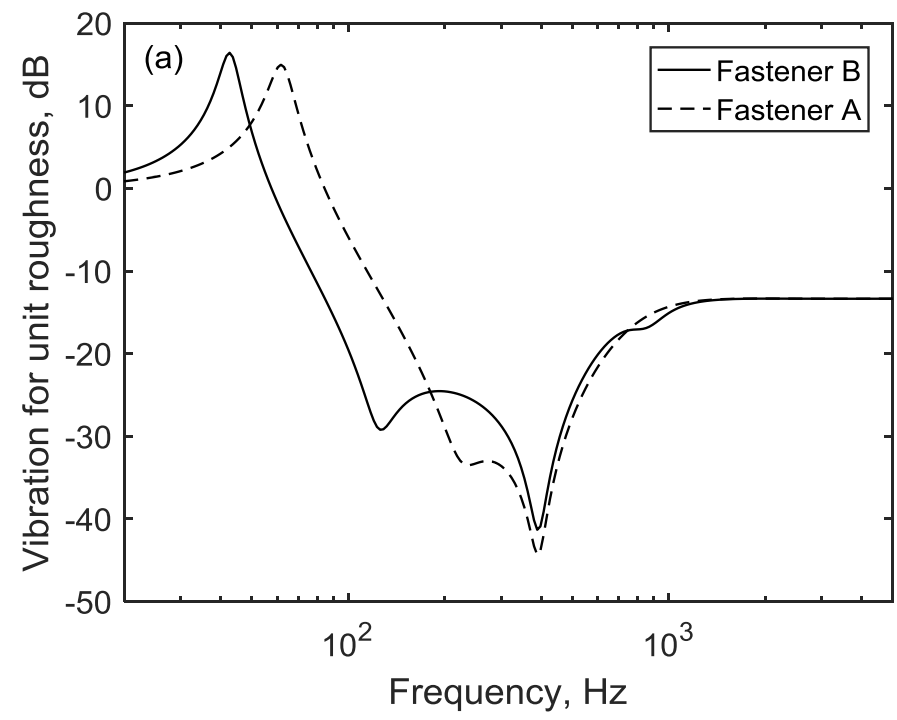


(b)

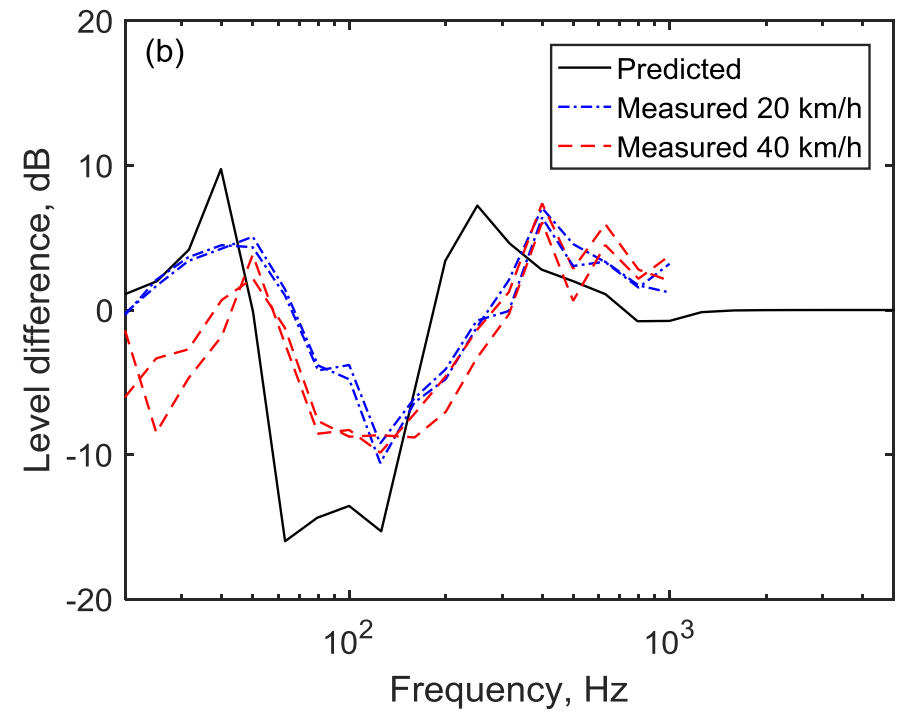

Fig. 22. (a) Estimates of axlebox vibration for a unit roughness input. (b) Level difference between the two rail fasteners (B minus A). Measured level differences are also shown.

\subsection{Rail vibration}

The rail vibration at the wheel/rail contact can similarly be obtained from the product of the wheel/rail force and the rail mobility. Results for a unit roughness are shown in Fig. 23(a). A peak is seen at the same resonance frequency as for the axlebox vibration. Above this frequency the rail vibration is approximately equal to the roughness for frequencies up to about $1 \mathrm{kHz}$; at higher frequencies the contact spring mobility is higher than that of the rail and the rail response drops with increasing frequency. However, the differences between the two fastener systems are limited to low frequencies.

The noise radiated by the track is determined by the average vibration over the length of the train. This is shown in Fig. 23(b). Where the track decay rate is lower (see Fig. 21(b)) the average vibration is greater. Thus Fastener $\mathrm{B}$ has a larger average response than Fastener A between 100 and $500 \mathrm{~Hz}$ and a smaller response between 500 and $2000 \mathrm{~Hz}$, in addition to the differences already seen at low frequencies. In Fig. 23(c) the level differences between the average rail vibrations for the two fastener systems are shown and compared with the measured results. Again these show similar trends, at least below $2 \mathrm{kHz}$.

(a)

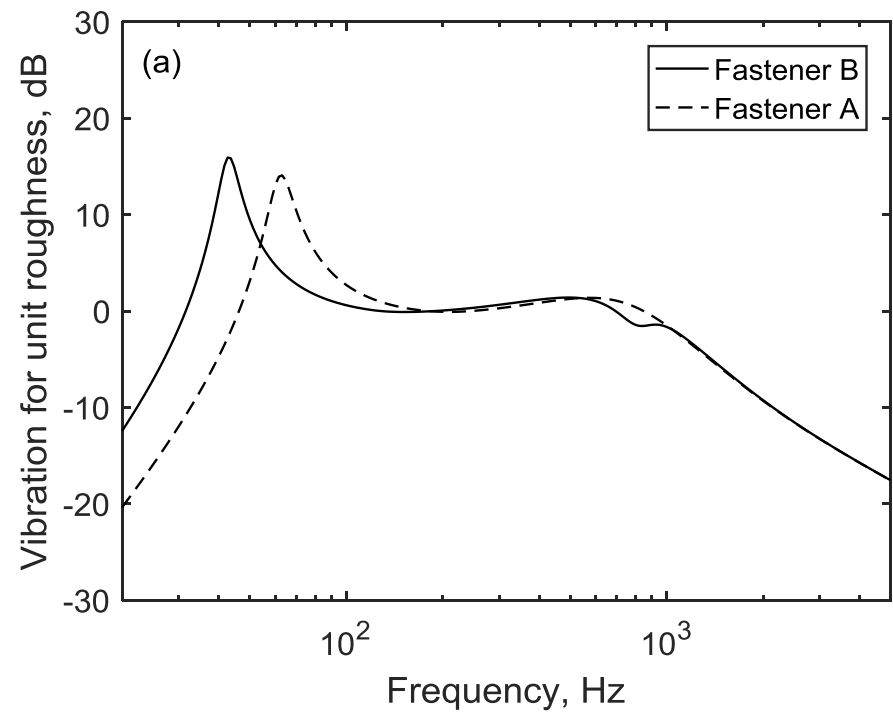


(b)

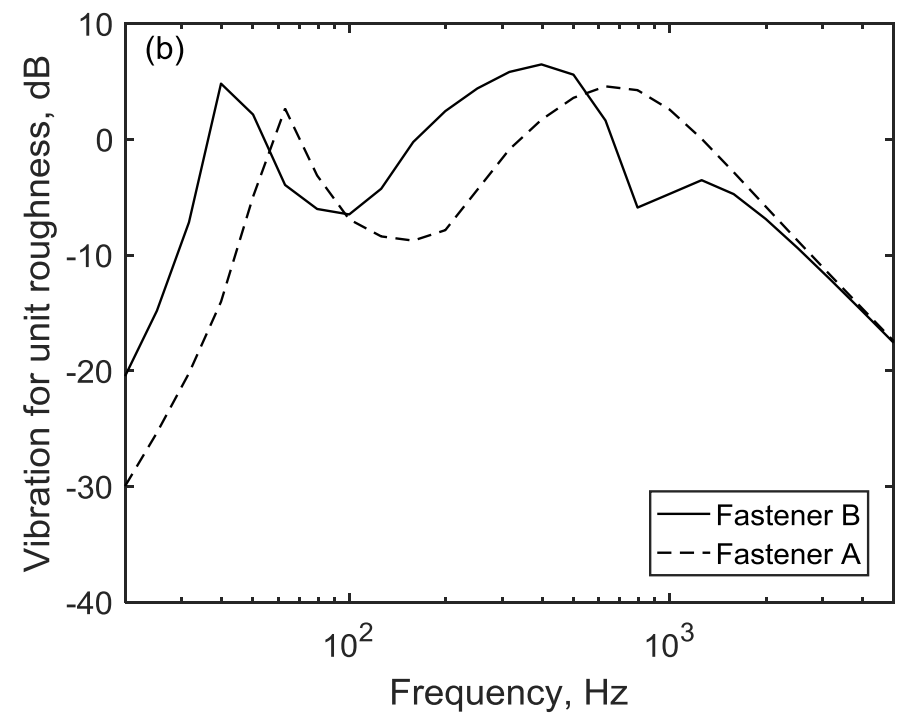

(c)

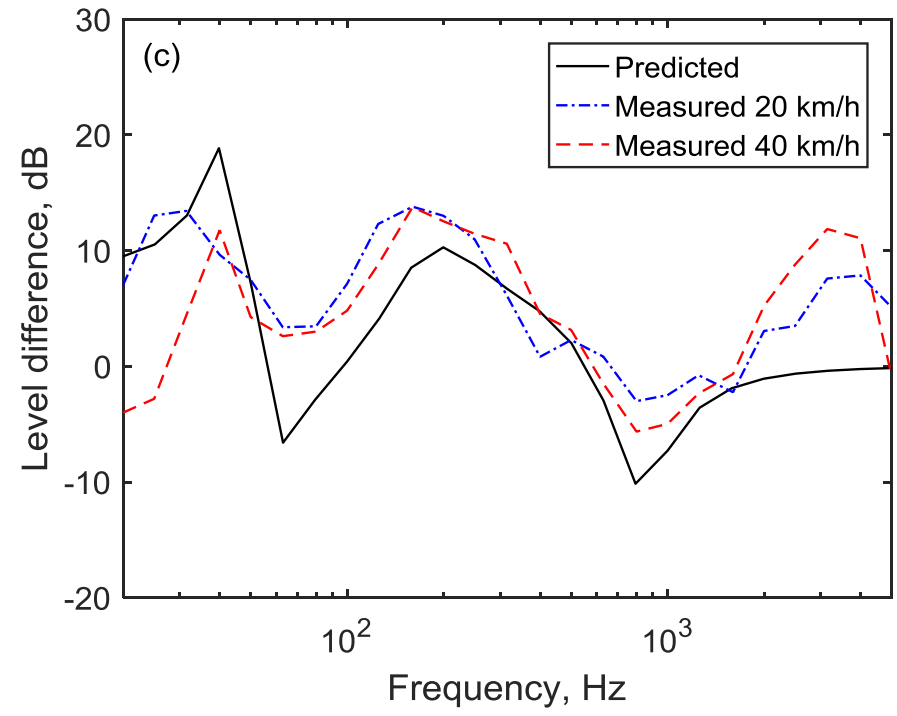

Fig. 23. Estimates of rail vibration for a unit roughness input. (a) Vibration at the wheel/rail contact point; (b) Average vibration over the length of one vehicle; (c) Level difference between the two rail fasteners (B minus A). Measured level differences are also shown.

\subsection{Rolling noise}

Finally the TWINS model [32] is used to predict the rolling noise. This includes the same track model used in the previous sections but the wheel is represented by a finite element model. As details of the wheel geometry are not available, a model of a similar wheel with the same diameter has been used. The lateral interaction force is also included in the model together with lateral dynamic properties of the wheel and track; however, the noise from the rail is dominated by its vertical vibration. The differences in average sound pressure level at positions P1 and P2 between the two fasteners are shown in Fig. 24 and compared with the corresponding measured differences. 
These predicted noise spectra show similar trends to the rail vibration, with the noise from fastener $B$ exceeding that from fastener $A$ in the frequency region 125 to $500 \mathrm{~Hz}$ and the opposite trend from 630 to $2000 \mathrm{~Hz}$. Above $2 \mathrm{kHz}$ the wheel noise dominates and there are negligible differences between the two fastener systems. The measured signals also show similar trends although the level differences are smaller than from the predicted results.

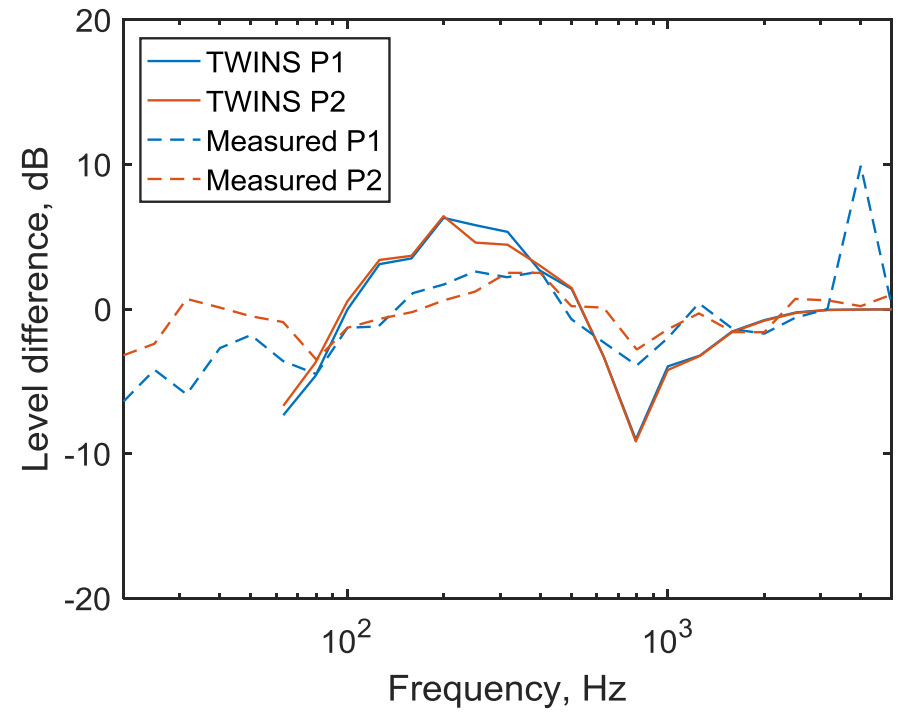

Fig. 24. External noise level differences (fastener B minus A) from TWINS and measurements

\subsection{Discussion}

As seen from the results in Figs 22-24, the structure-borne and airborne components of sound transmitted to the vehicle interior are expected to be affected differently by the change in fastener system. Changing from fastener $A$ to $B$, the axlebox vibration is reduced between 63 and $250 \mathrm{~Hz}$ and increased at higher frequencies. Conversely the rail vibration is increased for frequencies below $60 \mathrm{~Hz}$ and 100-600 Hz and reduced above $600 \mathrm{~Hz}$. The exterior rolling noise is increased between 100 and $600 \mathrm{~Hz}$ and reduce at other frequencies. As the interior noise above the bogie is increased between 100 and $2500 \mathrm{~Hz}$ on the whole, but there is a dip between two peaks, this suggests that both airborne and structure-borne noise components contribute to the interior sound. Perhaps surprisingly it appears from the shape of the difference spectra that airborne noise has most influence between 100 and 400 $\mathrm{Hz}$ and structure-borne noise has more influence between 500 and $1000 \mathrm{~Hz}$.

In the measurement situation, in which the train is located between two walls, the airborne sound transmitted through the doors and sidewalls will be greater than in free field but may be less than in a tunnel. In addition the situation in an operational line may involve different roughness on different tracks; corrugation is known to grow more rapidly on some track types and this may be a factor in the differences in rolling noise observed on some vibration-isolating tracks

\section{Conclusions}

The influence of rail fastener stiffness on railway vehicle interior noise has been investigated in a controlled study by a series of field measurements and numerical simulations. 
Comparative measurements were made on a test track in which only the rail fastener was changed. Besides the interior noise, the measurements also included the vibration of the vehicle floor, axlebox vibration, rail vibration and exterior noise, which help to give insight into the sources of interior noise.

From the interior noise measurement, it is found that when the softer rail fastener was used, the noise levels around $125 \mathrm{~Hz}$ and in the frequency range 315 to $1000 \mathrm{~Hz}$ were greater than those with the stiffer fastener The average level difference in the range 315 to $1000 \mathrm{~Hz}$ was $3 \mathrm{~dB}$. Similarly, from the measured vibration of the vehicle floor the vibration above the bogie with the more elastic fastener had a higher level than that with the stiffer one, with an average difference of $2.2 \mathrm{~dB}$ for all frequencies above $80 \mathrm{~Hz}$. In the middle of the vehicle, the vibration between $315 \mathrm{~Hz}$ and $1000 \mathrm{~Hz}$ was higher for the more elastic fastener.

Differences in axlebox vibration are indicative of differences in the structure-borne noise. The test results showed that, apart from a peak at $50 \mathrm{~Hz}$, the vibration for the stiffer fastener was generally greater below $250 \mathrm{~Hz}$ whereas that for the softer fastener was greater above $315 \mathrm{~Hz}$.

Exterior noise propagating into the vehicle through airborne transmission paths is another important source of interior noise. Rolling noise, due to vibration of the rails and wheels, is the most important component of the exterior noise. From the vertical rail vibration during train passages, the vibration with the softer fastener was larger below $500 \mathrm{~Hz}$, but smaller between 500 and $1600 \mathrm{~Hz}$. The exterior noise level difference showed a similar trend; the noise with the more elastic fastener was greater between $160 \mathrm{~Hz}$ and $500 \mathrm{~Hz}$ by up to 2.6 $\mathrm{dB}$, but was lower for frequencies above and below this range.

It is very difficult to build a sufficiently detailed and validated vehicle model as there are many parameters that influence the noise transmission. To give some insight into the measured results, models are used from the TWINS model for rolling noise considering the wheel/rail interaction. The aim is only to determine the differences in the predicted noise spectra. After adopting reasonable parameters the vibration of the axlebox and rail are predicted for a unit roughness input. Calculations of the noise indicate that the component due to the vertical vibration of the rail is dominant in much of the frequency range. The noise from the softer fastener exceeds that from the stiffer one in the frequency region 125 to 500 $\mathrm{Hz}$. The opposite trend occurs from 630 to $2000 \mathrm{~Hz}$ due to the presence of an internal resonance in the two-stage fastener, which gives an increase in the track decay rate. The measured signals also show similar trends although the level differences are smaller than those from the predicted results.

From the field measurements and the numerical simulations, it can be concluded that the more elastic fastener can cause increased noise in the vehicle interior, although at some frequencies the opposite occurs. The spectrum is influenced by both structure-borne and airborne paths, which are dominant in different frequency ranges.

\section{Acknowledgements}

This work was supported by National Natural Science Foundation of China (No. 51408434, No. 11772230, and No. 51678446), State Scholarship Fund of China (No. 201706265022) and National Science and Technology Support Program of China (No. 2015BAG19B02-03). 


\section{References}

[1] Hardy AEJ. Measurement and assessment of noise within passenger trains. J Sound Vib 2000; 231(3): 819-829.

[2] Eisenmann J, Steinbeisser L, Deischl F. Noise and vibration reducing track foundation for subways and rapid transit railways. Track Technology, Nottingham, UK; 1984.

[3] Sol-Sanchez M, Moreno-Navarro F, Rubio-Gamez MC. The use of elastic elements in railway tracks: A state of the art review. Construction and Building Materials 2015; 75: 293-305.

[4] Cox SJ, Wang A. Effect of track stiffness on vibration levels in railway tunnels. J Sound Vib 2003; 267: 565-573.

[5] Thompson DJ. Railway Noise and Vibration: Mechanisms, Modelling and Means of Control. Elsevier: Oxford, 2008.

[6] Terno HJ. State of the art review of mitigation measures on track (RIVAS Project Deliverable D3.1), 2011.

[7] Wang A, Cox SJ, Huang H, Liu L, Jiang J, Sun J. In-car noise and carriage floor vibration on different track forms and curvatures in a metro system. Notes on Numerical Fluid Mechanics and Multidisciplinary Design 2008; 99; 201-207.

[8] Eade PW, Hardy AEJ. Railway vehicle internal noise. J Sound Vib 1977; 51(3): 403-415.

[9] Färm J. Interior structure-borne sound caused by the sleeper-passing frequency. J Sound Vib 2000; 231(3): 831-837.

[10] Johansson A. Out-of-round railway wheels-assessment of wheel tread irregularities in train traffic. J Sound Vib 2006; 293(3-5): 795-806.

[11] Zhang J, Han GX, Xiao XB, Wang RQ, Zhao Y, Jin XS. Influence of wheel polygonal wear on interior noise of high-speed trains J Zhejiang Univ-Sci A (Appl Phy \& Eng) 2014; 15(12):1002-1018.

[12] Fan RP, Su ZQ, Meng G, He CC. Application of sound intensity and partial coherence to identify interior noise sources on the high speed train. Mechanical Systems and Signal Processing 2014; 46(2): 481-493.

[13] Ström R. Operational Transfer Path Analysis of Components of a High-speed Train Bogie. Sweden: Chalmers University of Technology; 2014.

[14] Kim HS, Yang SM and Kim BS. A study on interior noise characteristics of urban railway by rail track characteristics. Journal of the Korean Society of Mechanical Technology 2016; 18: 536-542 [in Korean].

[15] Noh HM, Choi S, Kim SW, Hong SY. A study on interior noise characteristics of high speed trains. Journal of the Korean Society for railway 2013; 16(1): 14-19 [in Korean].

[16] Zhang J, Xiao XB, Sheng XZ, Fu R, Yao D, Jin XS. Characteristics of interior noise of a Chinese high-speed train under a variety of conditions. J Zhejiang Univ-Sci A (Appl Phy \& Eng) $2017 ; 18(8):$ 617-630.

[17] Shi Y, Xiao YG, Chen FF, Zhang P. Interior noise prediction of subway cab caused by track irregularities. 2010 International Conference on Optoelectronics and Image Processing (ICOIP 2010), China, Haikou; 2010.

[18] Shi Y, Xiao YG, Kang ZC. Interior noise investigation for a passenger room of a highspeed train under wheel-rail excitation. Journal of Vibration and Shock 2009; 28: 95-98 [in Chinese]. 
[19] Liu CY, Wang TH, Bo ZZ, Liu JL. Internal low-frequency noise analysis of high-speed train under mechanical excitation. Journal of Vibroengineering 2014; 16(4):3086-3095.

[20] Grag VK, Dukipati RV, Dynamics of Railway Vehicle Systems. London: Academic Press: 1984.

[21] Zhang J, Xiao XB, Sheng XZ, Zhang CY, Wang RQ, Jin XS. SEA and contribution analysis for interior noise of a high-speed train. Appl Acoust 2016; 112: 158-170.

[22] Zheng X, Hao ZY, Wang X, Mao J. A full-spectrum analysis of high-speed train interior noise under multi-physical-field coupling excitations. Mechanical system and signal processing 2016; 75:525-543.

[23] Xie G, Thompson DJ, Jones CJC. A modelling approach for the vibroacoustic behaviour of aluminium extrusions used in railway vehicles. J Sound Vib 2006; 293(3-5): 921-932

[24] Kim K, Lee J, Kim D. A study on the vibroacoustic analysis of aluminium extrusion structures. Computer-Aided Design \& Applications 2012; 2:1-8.

[25] Zhang Y, Thompson D, Squicciarini G, Ryue J, Xiao X, Wen Z. Sound transmission loss properties of truss core extruded panels. Appl Acoust 2018; 131:134-153.

[26] Sui FS, Shen AN, Yuan MM. Low frequency sound radiation from aluminium extrusion, part I: experimental study. Proceeding of 20th International Congress on Acoustics, ICA 2010, Sydney, Australia, 2010.

[27] ISO 3381. Railway applications. Acoustics. Measurement of noise inside railbound vehicles. Switzerland: ISO (International Organization for Standardization); 2011.

[28] GB 14892. Noise limit and measurement for train of urban rail transit. China: Standardization Administration; 2006 [in Chinese]

[29] ISO 14837. Mechanical vibration-Ground-borne noise and vibration arising from rail system. Switzerland: ISO (International Organization for Standardization); 2005.

[30] TB/T 3396.3. Test methods for fastening systems of high-speed railway. Part 3: Determination of static stiffness for fastening assembly. China: Railway Industry for Standardization; 2015 [in Chinese]

[31] EN 13146-9+A1. Railway applications- Track-Test methods for fastening systems - Part 9: Determination of stiffness. European Committee for Standardisation; 2011.

[32] Thompson D, Hemsworth B, Vincent N. Experimental validation of the TWINS prediction program for rolling noise, part 1: description of the model and method. J Sound Vib 1996; 193: 123-135. 